\title{
ACS-TS: TRAIN SCHEDULING USING ANT COLONY SYSTEM
}

\author{
KEIVAN GHOSEIRI AND FAHIMEH MORSHEDSOLOUK \\ Received 6 July 2005; Revised 15 January 2006; Accepted 18 January 2006
}

This paper develops an algorithm for the train scheduling problem using the ant colony system metaheuristic called ACS-TS. At first, a mathematical model for a kind of train scheduling problem is developed and then the algorithm based on ACS is presented to solve the problem. The problem is considered as a traveling salesman problem (TSP) wherein cities represent the trains. ACS determines the sequence of trains dispatched on the graph of the TSP. Using the sequences obtained and removing the collisions incurred, train scheduling is determined. Numerical examples in small and medium sizes are solved using ACS-TS and compared to exact optimum solutions to check for quality and accuracy. Comparison of the solutions shows that ACS-TS results in good quality and time savings. A case study is presented to illustrate the solution.

Copyright (c) 2006 K. Ghoseiri and F. Morshedsolouk. This is an open access article distributed under the Creative Commons Attribution License, which permits unrestricted use, distribution, and reproduction in any medium, provided the original work is properly cited.

\section{Introduction}

In this section a hierarchical process of rail transport planning is introduced and then the ant's behavior which gives inspiration for ant algorithms is presented.

1.1. Rail transport planning. Rail transport planning is a very complex task which is carried out based on the mutual reaction among a large number of impressed components. As it was mentioned in Ghoseiri et al. [51] and Lindner [70], in respect to the complexity of rail transport planning, this process is divided into several steps. These procedures include the demand analysis, line planning, train scheduling, rolling stock planning, and crew management. Figure 1.1 shows this decomposition. The following is a brief description on the hierarchical planning process.

In the first step, the passenger demand is analyzed. As a result, the amount of passenger's demand between certain origins and certain destinations is determined. The line 

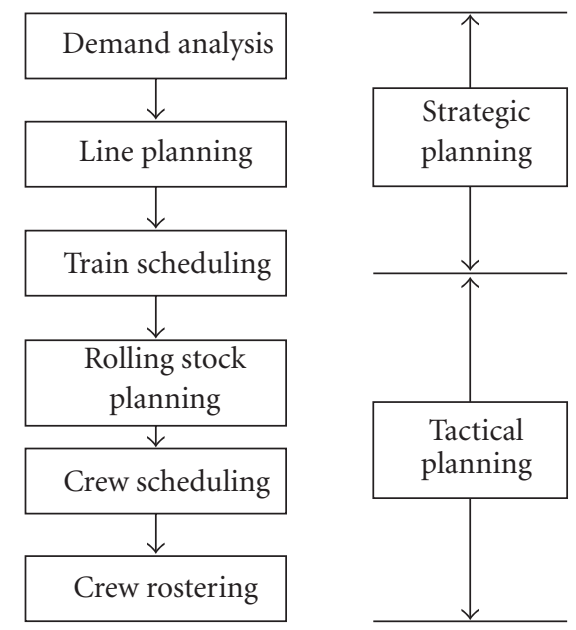

FIGURE 1.1. The hierarchical planning process in public rail transport (adapted from Ghoseiri et al. [51]).

planning includes decision making about routes and lines. This planning identifies which routes or lines should be exploited with what frequency. In the train scheduling phase, the arrival and departure times for all trains are determined. Determination of a timetable to separate the arrival and departure times of starting, ending, and middle stations is the product of this phase. In the next phase, the wagons and locomotives which are dedicated to the line are linked together to form a train. This phase is called rolling stock planning. The next task is the crew management. This task determines the distribution and allocation of the train's crew. This planning should be done in a way that supplies the necessary staff for each train. Crew management components include crew scheduling and crew rostering. Crew scheduling results in allocation of crews to trains and crew rostering determines their duty description. All of these phases have a close relationship. Computing an optimal solution in one phase may restrict the feasible solution space in the next phases.

Another classification was done by Assad [3]. Assad divided the planning process of rail transportation into strategic, tactical, and operational levels. This classification is shown in Table 1.1.

In the strategic planning level, some decisions are made about infrastructure investments. These decisions are long-term decisions, so they require greater costs. These decisions are greatly affected by political considerations. The infrastructure of the network develops in this phase. The analysis of passenger demand and the design of line plans also belong in this planning level. The tactical planning level is in fact the resource allocation phase. Most of line planning details and train schedule planning is done in this phase. Operational planning is just the day-by-day decisions. Here, due to unexpected events like breakdowns, special trains, or short-term changes in the infrastructure caused 
TABLE 1.1. Planning levels (adapted from Assad [3]).

\begin{tabular}{lcc}
\hline Planning stages & Time horizon & Objective \\
\hline Strategic level & $5-15$ years & Resource acquisition \\
Tactical level & $1-5$ years & Resource allocation \\
Operational level & 24 hours-1 year & Daily planning \\
\hline
\end{tabular}

by construction sites, certain parts of the schedule, rolling stock, or crew assignment patterns have to be rearranged. (For further study refer to Ghoseiri et al. [51] and Lindner [70].)

1.2. Ant's behavior. Special insects like ants, termites, and bees that live in a colony are capable of solving their daily complex life problems. These behaviors which are seen in a special group of insects are called swarm intelligence. Swarm intelligence techniques focus on the group's behavior and study the decartelized reactions of group agents with each other and with the environment. The swarm intelligence system includes a mixture of simple local behaviors for creating a complicated general behavior and there is no central control in it. Various types of certain ants have the ability to deposit pheromone on the ground and to follow, in probability, pheromone previously deposited by other ants. By depositing this chemical substance, the ants leave a trace on their paths. By detecting this trace, the other ants of the colony can follow the path discovered by other ants to find food. For finding the shortest way to get food, these ants can always follow the pheromone trails. (For further study refer to Fabinkue [42], Dorigo and Di Caro [34].) As was mentioned in Dorigo et al. [35], the ant algorithms based on this characteristic are inspired from Goss experiments, a laboratory colony of Argentine ants called Iridomyrmex Hmilis was placed in a closed space in which the nest was connected to food resource by a double bridge (with different length). This branched way was designed in a way that the ants could just choose one of the branches for reaching the food. After several times carrying out the experiment, the number of ants and amount of pheromone in each branch were counted and measured. It was also observed in this experiment that the possibility of choosing the shortest path increases with the length difference of two branches.

The reason for this behavior in ants is explained in the following form: in the beginning of the experiment, there is no pheromone in each branch. For this reason the ants choose one of the paths without any preferences and with an equal probability. So it can be expected that in the beginning of experiment half of the ants choose the longer branch and another half of ants choose the shorter branch. Because of shortness of one of the paths, the ants that have chosen the shorter path reach the food resource earlier and return to the nest. When these ants want to choose one of the ways to reach the food, the presence of pheromone in the shorter branch makes ants interested in choosing this branch. Therefore the amount of pheromone in this path increases more quickly and finally makes the majority of ants choose this path. Figure 1.2 shows the reason for this behavior in ants. 


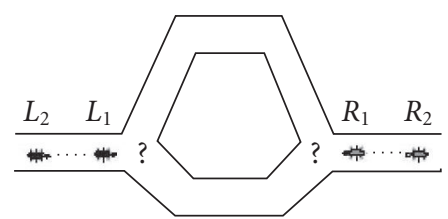

(a)

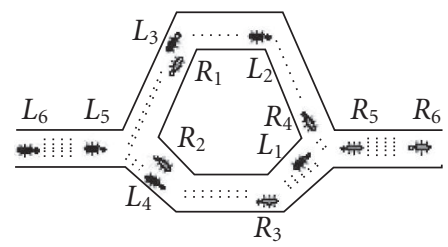

(c)

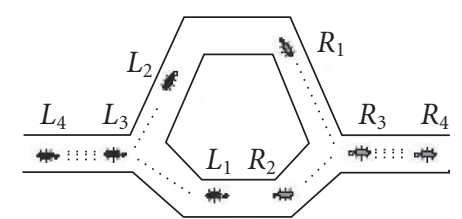

(b)

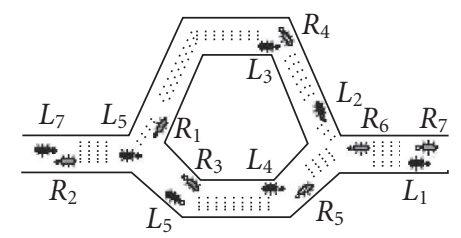

(d)

Figure 1.2. The ant's behavior: (a) the ants reach to the point of making a decision. (b) The ants choose one of the two paths randomly. (c) If the ants move with the same speed, the ants which have chosen the shorter path reach sooner to the point of making next decision. (d) The amount of pheromone in the shorter branch increases at a higher rate. (Adapted from Dorigo and Gambardella [36].)

\section{Literature review}

In this section, first there is a review on the literature of the train scheduling problem and then the manner of creating, developing, and applying the ant algorithms is put forward. The literature review of the train scheduling problem and the ant algorithms show that ant colony optimization algorithms currently are not used for solving the train schedule problem.

2.1. Train scheduling. The train schedule problem is one of the difficult problems in rail transport planning. This planning has been carried out manually and by trial and error methods for over a century. In a manual method, the train arrival and departure times from each station are identified based on the individual's experience and information. The solution quality and building time in this method are closely related to the individual's experience and ideas. (For a further study refer to Chiang et al. [20].)

Mathematical programming, simulation, expert systems, heuristic and metaheuristic methods, and combinational methods are other techniques for train scheduling. Mathematical methods give exact or optimal solutions. Examples of these methods include Frank [45], Amit and Goldfarb [1], Szpigel [104], Petersen [88], Chen and Harker [18], Keaton [64], Kraay and Harker [67], Lindner [70], Brodal and Jacob [14], and Ghoseiri et al. [51]. Although these techniques consistently find solutions with high quality, the time and memory used in these methods for solving realistically sized problems is very high. For these reasons, simulation, heuristic, metaheuristic methods and expert systems are typically used for solving these problems. (For a further study refer to Cordeau et al. [23].) 
The application of simulation during the 1970s faced failure when solving the train scheduling problem. In these years, simulation had impractical application because of extra calculations and informational necessities. However, today computers can implement the simulation models much easier. Databases can be combined with other programs and this leads to a considerable improvement in simulation technology. There are several researches using simulations in the rail network literature; Peat, Marwick, Mitchell \& Co. [87], Jovanovic and Harker [63], Dessouky and Leachman [28], Cheng [19], Higgins and Kozan [56].

Heuristic methods are not always able to give good solutions to problems but these algorithms may solve the problem in a shorter time. This property makes these algorithms play a more constructive part of the primary solutions for other algorithms. These algorithms are made based on the problem structure and have a different structure for each problem. These algorithms' applications to railway problems can be noted in Cai and Goh [16], Carey and Lockwood [17], and Higgins et al. [57].

Knowledge-based systems (expert systems) have typically been used to solve problems that are either too complex for a mathematical formulation or too difficult to be solved by optimization approaches. Some examples of application of the knowledge-based systems in railway transportation are Cury et al. [26], Araya and Abe [2], Iida [59], Komaya and Fukuda [65], Minton et al. [79], Zweben et al. [114]. These algorithms are considered as a subgroup of heuristic algorithms. (For a further study refer to Chiang et al. [20].)

Metaheuristics are in fact guide algorithms of heuristic algorithms. These algorithms use the heuristic parts and give them direction in the searches. In spite of that, the heuristic parts of these algorithms have a specific and fixed structure and they can be used for solving various problems with little changes. These algorithms are inspired by events of nature. Some of these algorithms include genetic algorithm, neural networks, immune system, tabu search, simulation annealing and ant colony optimization. Although the solution quality of these algorithms is high and produces solutions close to optimum, there is still little metaheuristic research on rail transport planning problems. As an example, Huntley et al. [58] developed a simulated annealing approach to train scheduling for CSX transportation. Van Wezel et al. [108] applied a genetic algorithm to improve train timetables. Martinelli and Teng [76] used neural networks for routing in a railway. Nachtigall and Voget [83] applied a genetic algorithm to solve train scheduling problems. Gorman [52] used a combination of a genetic algorithm and tabu search for addressing the weekly routing and scheduling problem. Pacciarelli and Pranzo [86] used tabu search to solve train scheduling problem. Kwan and Mistry [68] used a coevolutionary algorithm to create a train timetable. Sepehri [95] solved the crew planning problem in a railway by ant colony optimization. Engelhardt-Funke and Kolonko [41] used an advanced evolutionary algorithm to solve train scheduling problem. Dorigo and Gambardella [36], as it can be seen in Table 2.1, showed that the ACS algorithm has been more successful than the other metaheuristics in solving the TSP. In this table, for each of the problems tested, the best solution and its corresponding iteration number built using the metaheuristics is reported. Additionally, Fischetti et al. [43], Gutin and Punnen [54], and Noon and Bean [85] showed that the train scheduling problem can be easily transformed to a travel salesman problem. Therefore, considering the approach of transforming the train scheduling 
Table 2.1. Comparison of metaheuristic algorithms (adapted from Dorigo and Gambardella [36]).

\begin{tabular}{l|ccccc}
\hline Problem name & SA & EP & GA & ACS & Optimal \\
\hline \multirow{2}{*}{ TSP with 50 cities } & 443 & 426 & 428 & 425 & \multirow{2}{*}{ TSP with 75 cities } \\
\multirow{2}{*}{ TSP with 100 cities } & 58512 & 100000 & 2500 & 1830 & \\
& 173250 & 325000 & 80000 & 3480 & 535 \\
& NA & NA & 21761 & 21282 & 21282 \\
\hline
\end{tabular}

problem to a TSP problem, good responses can be expected from solving it using the ACS algorithm.

In this research, it is decided to solve the train scheduling problem by this algorithm based on the good results using the ACS algorithm to solve the TSP problem and also transforming capability of the train scheduling problem to a TSP.

2.2. Historical development of ant colony optimization. Ant algorithms are a population-based approach which has been successfully applied to several NP-hard combinatorial optimization problems. As the name suggests, ant algorithms have been inspired by the behavior of real ant colonies. One of the main ideas of ant algorithms is the indirect communication of a colony of agents, called (artificial) ants, based on pheromone trails (pheromones are also used by real ants for communication). The (artificial) pheromone trails are a kind of distributed numeric information which is modified by the ants to reflect their experience while solving a particular problem. The first ACO algorithm, called ant system (AS) has been applied to the traveling salesman problem (TSP) by Dorigo et al. [38]. In spite of hopeful results, the algorithm results were not comparable to the other advanced algorithms which were already applied to solve this problem. Despite the fact, this algorithm built important principles in creating more advanced algorithms. At the present time, many algorithms have been suggested based on the improvement of AS algorithm and used for solving various problems. A comprehensive list of ACO algorithms and their applications are shown in Table 2.2.

\section{ACS compound model and train scheduling problem}

Train scheduling is a combinatorial optimization problem. In this problem the aim is to determine the arrival and departure times from stations on which the train passes. This problem is known to be NP-hard. Because of the dimensions and natural complexity in mathematical models, traditional optimization techniques are not useful for solving the problem, and the exact methods are only usable with examples in small sizes. For solving the problem with real dimensions, the heuristic or metaheuristic methods should be used. In this research, the ACS algorithm is chosen as the metaheuristic method for solving the train scheduling problem. 
TABLE 2.2. Ant algorithms and their applications.

\begin{tabular}{|c|c|c|c|c|}
\hline Algorithm name & Developer(s) & Year & Problem & Reference \\
\hline \multirow{3}{*}{ Ant system } & Dorigo et al. & 1991 & Traveling salesman problem & {$[38]$} \\
\hline & Forsyth and Wren & 1997 & Bus driver scheduling & {$[44]$} \\
\hline & Nahas and Nourelfath & 2005 & $\begin{array}{l}\text { Reliability optimization of } \\
\text { a series system }\end{array}$ & {$[84]$} \\
\hline AS-QAP & Maniezzo et al. & 1994 & $\begin{array}{l}\text { Quadratic assignment } \\
\text { problem }\end{array}$ & {$[75]$} \\
\hline AS-JSP & Colorni et al. & 1994 & Job shop scheduling problem & {$[22]$} \\
\hline Ant-Q & Dorigo, Gambardella & 1997 & Traveling salesman problem & {$[36]$} \\
\hline $\begin{array}{l}\text { ACS-3opt } \\
\text { and ACS }\end{array}$ & Dorigo, Gambardella & 1997 & Traveling salesman problem & {$[36,37]$} \\
\hline $\mathrm{ABC}$ & Schoonderwoerd et al. & 1996 & Telecommunications networks & {$[94]$} \\
\hline AS-VRP & Bullnheimer et al. & 1997 & Vehicle routing problem & {$[15]$} \\
\hline MMAS & Socha et al. & 2003 & $\begin{array}{l}\text { University course timetabling } \\
\text { problem }\end{array}$ & {$[98]$} \\
\hline HAS_QAP & Gambardella et al. & 1999 & $\begin{array}{l}\text { Quadratic assignment } \\
\text { problem }\end{array}$ & {$[48]$} \\
\hline HAS_SOP & Gambardella and Dorigo & 2000 & Sequential ordering problem & {$[46]$} \\
\hline AS-ATP & Costa and Hertz & 1997 & Graph coloring & {$[25]$} \\
\hline ANTCOL & Costa and Hertz & 1997 & Graph coloring & {$[25]$} \\
\hline $\begin{array}{l}\text { AntNet \& } \\
\text { AntNet-FA }\end{array}$ & Di Caro and Dorigo & 1997 & $\begin{array}{l}\text { Connectionless network } \\
\text { routing }\end{array}$ & {$[29]$} \\
\hline Regular ants & Subramanian et al. & 1977 & Routing in dynamic network & {$[103]$} \\
\hline MMAS-QAP & Stutzle and Hoos & 2000 & $\begin{array}{l}\text { Quadratic assignment } \\
\text { problem }\end{array}$ & {$[102]$} \\
\hline AS-QAP & Maniezzo and Colorni & 1999 & $\begin{array}{l}\text { Quadratic assignment } \\
\text { problem }\end{array}$ & {$[74]$} \\
\hline \multirow[t]{2}{*}{ ANTS-QAP } & Maniezzo & 1999 & $\begin{array}{l}\text { Quadratic assignment } \\
\text { problem }\end{array}$ & {$[71]$} \\
\hline & Solimanpur et al. & 2004 & $\begin{array}{l}\text { Intercell layout problem in } \\
\text { cellular manufacturing }\end{array}$ & [99] \\
\hline AS-SCS & Michel and Middendorf & 1999 & $\begin{array}{l}\text { Shortest super sequence } \\
\text { problem }\end{array}$ & {$[78]$} \\
\hline ASGA & White et al. & 1998 & Connection management & [111] \\
\hline AntNet-FS & Di Caro and Dorigo & 1998 & $\begin{array}{l}\text { Connection-oriented network } \\
\text { routing }\end{array}$ & {$[30]$} \\
\hline $\mathrm{ABC}$-smart ants & Bonabeau et al. & 1988 & $\begin{array}{l}\text { Connection-oriented network } \\
\text { routing }\end{array}$ & {$[13]$} \\
\hline CAF & Heusse et al. & 1998 & Routing networks & {$[55]$} \\
\hline ABC-backward & Van der Put & 1998 & Routing in the faxfactory & [107] \\
\hline
\end{tabular}


TABle 2.2. Continued.

\begin{tabular}{|c|c|c|c|c|}
\hline Algorithm name & Developer(s) & Year & Problem & Reference \\
\hline \multirow{15}{*}{ ACO } & Stutzle & 1998 & Flow shop problem & {$[101]$} \\
\hline & Bland & 1999 & Space-planning & {$[10]$} \\
\hline & Doerner et al. & 2003 & Full truckload transportation & {$[33]$} \\
\hline & Doerner et al. & 2000 & Pickup and delivery & {$[32]$} \\
\hline & Jayaraman et al. & 2001 & Bioreactors optimization & {$[60]$} \\
\hline & Bland & 2001 & Structural design problem & {$[11]$} \\
\hline & Gravel et al. & 2002 & Scheduling continuous casting & {$[53]$} \\
\hline & Roli et al. & 2001 & Constraint satisfaction & {$[92]$} \\
\hline & Gamez and Puerta & 2002 & Best elimination sequence & {$[49]$} \\
\hline & Eggers et al. & 2003 & $\begin{array}{l}\text { Keyboard arrangement } \\
\text { problem }\end{array}$ & {$[40]$} \\
\hline & Shelokar et al. & 2004 & Clustering & {$[96]$} \\
\hline & Gandibleux et al. & 2004 & Set packing problem & {$[50]$} \\
\hline & Reimann and Laumanns & 2005 & $\begin{array}{l}\text { Capacitated minimum } \\
\text { spanning tree problem }\end{array}$ & {$[90]$} \\
\hline & Lim et al. & 2005 & Bandwidth minimization & {$[69]$} \\
\hline & Baykasoglu et al. & 2005 & $\begin{array}{l}\text { Dynamic facility layout } \\
\text { problem }\end{array}$ & {$[6]$} \\
\hline AS(TS) & Bland & 1999 & Layout of facilities & {$[9]$} \\
\hline Intelligent ant & Zhou and Liu & 1998 & $\begin{array}{l}\text { Dynamic routing of } \\
\text { telecommunication networks }\end{array}$ & {$[113]$} \\
\hline MACS-VRPTW & Gambardella et al. & 1999 & Vehicle routing problem & {$[47]$} \\
\hline ACSp & Bianchi et al. & 2004 & $\begin{array}{l}\text { Probabilistic traveling } \\
\text { salesman problem }\end{array}$ & {$[8]$} \\
\hline API & Monmarché et al. & 2000 & Numeric optimization & {$[80]$} \\
\hline BWAS & Cordon et al. & 2000 & Traveling salesman problem & {$[24]$} \\
\hline Painter ants & Tzafestas & 2000 & Digital art & {$[106]$} \\
\hline \multirow[t]{2}{*}{ CACO } & Jayaraman et al. & 2000 & $\begin{array}{l}\text { Design and scheduling of } \\
\text { batch plants }\end{array}$ & {$[61]$} \\
\hline & Vijayakumar et al. & 2003 & Multipass turning operations & [109] \\
\hline Cognitive map & Ramos and Almeida & 2000 & $\begin{array}{l}\text { Image segmentation-pattern } \\
\text { reorganization }\end{array}$ & {$[89]$} \\
\hline \multirow[t]{3}{*}{ ANTS } & Maniezzo and Carbonaro & 2000 & $\begin{array}{l}\text { Frequency assignment } \\
\text { problem }\end{array}$ & {$[72]$} \\
\hline & Maniezzo et al. & 2001 & Data warehouse logical design & {$[73]$} \\
\hline & Montemanni et al. & 2002 & $\begin{array}{l}\text { Minimum-span frequency } \\
\text { assignment }\end{array}$ & {$[82]$} \\
\hline AS-VRPB & Wade and Salhi & 2004 & Vehicle routing problem & {$[110]$} \\
\hline ACSA & Yu and Song & 2001 & $\begin{array}{l}\text { Short-term schedule of } \\
\text { thermal units }\end{array}$ & {$[112]$} \\
\hline
\end{tabular}


TABle 2.2. Continued.

\begin{tabular}{|c|c|c|c|c|}
\hline Algorithm name & Developer(s) & Year & Problem & Reference \\
\hline AntNet routing & Barán and Sosa & 2001 & Data networks routing & {$[5]$} \\
\hline $\mathrm{AC}^{2}$ & Cicirello & 2001 & Shop floor routing & {$[21]$} \\
\hline Anthill & Baboglu et al. & 2001 & Peer-to-peer (P2P) networks & {$[4]$} \\
\hline \multirow{2}{*}{$\begin{array}{l}\text { Multiple ant } \\
\text { colony }\end{array}$} & Jong and Wiering & 2001 & Bus stop allocation problem & {$[62]$} \\
\hline & Bell and McMullen & 2004 & Vehicle routing problem & {$[7]$} \\
\hline Parallel ant colonies & Talbi et al. & 2001 & $\begin{array}{l}\text { Quadratic assignment } \\
\text { problem }\end{array}$ & {$[105]$} \\
\hline Ant heuristic & McMullen & 2001 & JIT sequencing problem & {$[77]$} \\
\hline Ant-TDVRP & Rizzoli et al. & 2002 & Vehicle routing problem & {$[91]$} \\
\hline ACS-DVRP & Montemanni et al. & 2002 & $\begin{array}{l}\text { Dynamic vehicle routing } \\
\text { problem }\end{array}$ & {$[81]$} \\
\hline ACO-B & De Campos et al. & 2002 & Learning Bayesian networks & [27] \\
\hline Multilevel ant-colony & Korosec et al. & 2004 & Mesh-partitioning problem & {$[66]$} \\
\hline Pareto ACO & Doerner et al. & 2005 & Project portfolio selection & {$[31]$} \\
\hline Population-based & Scheuermann et al. & 2004 & $\begin{array}{l}\text { Field-programmable gate } \\
\text { arrays }\end{array}$ & {$[93]$} \\
\hline CIAC & Dréo and Siarry & 2004 & $\begin{array}{l}\text { Optimization of multiminima } \\
\text { continuous functions }\end{array}$ & {$[39]$} \\
\hline RPACO & Shi et al. & 2004 & $\begin{array}{l}\text { Unit commitment with proba- } \\
\text { bilistic spinning reserve }\end{array}$ & {$[97]$} \\
\hline Beam-ACO & Blum & 2005 & Open shop scheduling & {$[12]$} \\
\hline Ant algorithm & Solimanpur et al. & 2005 & $\begin{array}{l}\text { Layout problem in flexible } \\
\text { manufacturing systems }\end{array}$ & {$[100]$} \\
\hline
\end{tabular}

3.1. Ant colony system (ACS). ACS was suggested as a new heuristic method to solve optimization problems by Dorigo and Gambardella $[36,37]$. The reformed form of the AS algorithm and functions is as follows.

Each ant generates a complete solution by choosing the nodes according to a probabilistic state transition rule. The state transition rule given in (3.1) and (3.2) is called a pseudorandom-proportional rule:

$$
\begin{gathered}
s= \begin{cases}\arg \left[\operatorname{Max}_{j \in N_{i}^{k}}\left\{\left[\tau_{i j}\right]\left[\eta_{i j}\right]^{\beta}\right\}\right] & \text { if } q \leq q_{0}, \\
S & \text { if } q>q_{0},\end{cases} \\
p_{i j}^{k}=\frac{\left[\tau_{i j}\right]\left[\eta_{i j}\right]^{\beta}}{\sum_{l \in N_{i}^{k}}\left[\tau_{i j}\right]\left[\eta_{i j}\right]^{\beta}},
\end{gathered}
$$

where $q$ is a random number uniformly distributed in $\left[\begin{array}{lll}0 & \cdots & 1\end{array}\right], q_{0}$ is a parameter between 0 and $1, S$ is a random variable selected according to the probability distribution given in (3.2), $\tau_{i j}$ is the amount of pheromone in edge $i j, \eta_{i j}=1 / \delta_{i j}$ where $\delta_{i j}$ is the cost of edge $i j, \beta$ is a parameter that determines the relative importance of $\eta$ versus $\tau$, and 


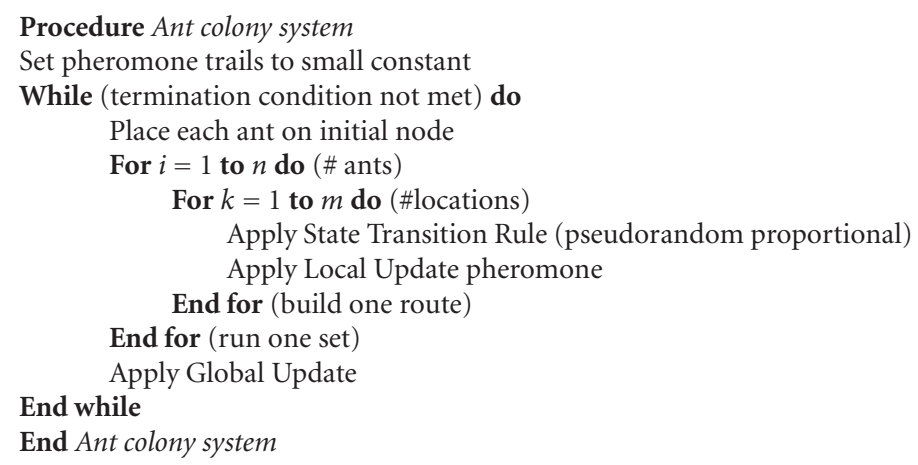

Algorithm 3.1. ACS algorithm procedure.

$N_{i}^{k}$ is the remaining node set of ant $k$ based on moving from node $i$ to build a feasible solution.

In ACS, only the globally best ant which has built the best solution deposits pheromone in the graph. At the end of an iteration of the algorithm, once all the ants have built a solution, pheromone is added to the arcs used by the ant that found the best tour from the beginning of the trial. This updating rule is called the global updating rule of pheromone:

$$
\tau_{i j} \longleftarrow(1-\rho) \tau_{i j}+\rho \Delta \tau_{i j}
$$

where $0<\rho<1$ is a pheromone decay parameter and $\Delta \tau_{i j}$ equals to

$$
\Delta \tau_{i j}= \begin{cases}\frac{1}{\cos t_{\mathrm{gb}}} & \text { if }(i, j) \in \psi^{\mathrm{gb}}, \\ 0 & \text { if }(i, j) \notin \psi^{\mathrm{gb}},\end{cases}
$$

$\psi^{\mathrm{gb}}$ is the best solution which was built and $\cos t_{\mathrm{gb}}$ is the cost of the best solution.

In ACS, ants perform step-by-step pheromone updates using local updating rule of pheromone. These updates are performed to favor the emergence of other solutions than the best so far. The updates result in step-by-step reduction of the pheromone level of the visiting edges by each ant. The local updating rule of pheromone is performed by applying the rule

$$
\tau_{i j} \longleftarrow(1-\xi) \tau_{i j}+\xi \tau_{0},
$$

$\tau_{0}$ is a small fixed value and $0<\xi<1$ is the local evaporation coefficient of pheromone. The ACS's overall structure is shown in Algorithm 3.1.

3.2. The proposed mathematical model of train scheduling. In this section a mathematical model for train scheduling on a single track line is presented. This model is the work done by Higgins and Kozan [56] with minor changes in order to account for the 
assumptions of the model. In this model it is supposed that the trains are only dispatched from the first and last station. After preparation, the trains in the beginning or end stations should be dispatched immediately. In the case that the prepared trains to dispatch are stopped in the stations with unpermitted time stop and go over the allowed time, we undergo some cost. In this model, the speed and trip times in each track section for each train are assumed to be fixed. Also, a train can travel in two directions, but it is not permitted to overtake another train. (For further study refer to Higgins and Kozan [56].)

\subsubsection{Notations.}

$R$ : the group of trains that should be dispatched from right station to left.

$L$ : the group of trains that should be dispatched from left station to right.

$T$ : the group of total trains $(i, j \in R$ or $L$ or $T$ and $T=R \cup L)$.

$S$ : set of stations $(k \in S)$, track sections and stations are indexed in numerical order from left to right.

Track section $k$ is a section of track that connects two stations $k$ and $k+1$.

$D$ : the set of permitted stop times in the station $\left(d_{i k} \in D\right)$.

$\mathrm{AD}$ : the set of arrival and departure times from a station $(X a(i, k), X d(i, k) \in \mathrm{AD})$.

$M$ : a big positive number.

\subsubsection{Parameters.}

Trip time: the time that train $i$ needs to pass track section $k \cdot\left(t_{i k}\right)$.

Dwell time: this time indicates the permitted dwell time of train $i$ in station $k \cdot\left(d_{i k}\right)$.

Headway: minimum time interval between trains $i$ and $j$ to arrive/depart from track section $k \cdot\left(h_{i j k}\right)$.

Train importance weight: $\left(W_{i}\right)$.

\subsubsection{Decision making variables}

Binary variables.

$$
\begin{aligned}
& a_{i j}= \begin{cases}1 & \text { if train } j \in R \text { enters the track section after train } i \in R, \\
0 & \text { otherwise, }\end{cases} \\
& b_{i j}= \begin{cases}1 & \text { if train } j \in L \text { enters the track section after train } i \in L, \\
0 & \text { otherwise, }\end{cases} \\
& c_{i j k}= \begin{cases}1 & \text { if train } j \in L \text { enters the track section } k \text { after train } i \in R, \\
0 & \text { otherwise (i.e., train } i \in R \text { enters the track section } k \text { after } \operatorname{train} j \in L) .\end{cases}
\end{aligned}
$$

\section{Continuous variables.}

$\mathrm{Xa}(\mathrm{i}, \mathrm{k})$ : the arrival time of train $i$ to station $\mathrm{k}$.

$\mathrm{Xd}(\mathrm{i}, \mathrm{k})$ : the departure time of train $i$ from station $\mathrm{k}$.

3.2.4. Objective function. Objective function in this model is to minimize the total train delays in the stations. The delay equals the time difference between the amounts of time 
a train is stopped and its permitted dwell time in the station

$$
\operatorname{Min} z=\sum_{i \in T} \sum_{k \in S} W_{i}\left(X d(i, k)-X a(i, k)-d_{i k}\right)
$$

3.2.5. Constraints. Trip-times constraints of dispatched trains from the right station:

$$
X a(i, k)-X d(i, k-1)=t_{i k}, \quad i \in R, k \in S .
$$

Trip-times constraints of dispatched trains from left station:

$$
X a(i, k-1)-X d(i, k)=t_{i k}, \quad i \in L, k \in S .
$$

Stop-times constraints of dispatched trains from left and right stations:

$$
X d(i, k)-X a(i, k) \geq d_{i k}, \quad i \in T, k \in S \text {. }
$$

Sequence constraints of dispatched trains from right station:

$$
\begin{gathered}
X d(j, k-1)-X a(i, k) \geq h_{i j k}-M\left(1-a_{i j}\right), \quad i, j \in R, k \in S, \\
X d(i, k-1)-X a(j, k) \geq h_{i j k}-M a_{i j}, \quad i, j \in R, k \in S .
\end{gathered}
$$

Sequence constraints of dispatched trains from left station:

$$
\begin{gathered}
X d(j, k)-X a(i, k-1) \geq h_{i j k}-M\left(1-b_{i j}\right), \quad i, j \in L, k \in S \\
X d(i, k)-X a(j, k-1) \geq h_{i j k}-M b_{i j}, \quad i, j \in L, k \in S .
\end{gathered}
$$

Safety constraints that ensure no collision occurs between two trains of opposite directions:

$$
\begin{gathered}
X d(i, k)-X a(j, k) \geq h_{i j k}-M c_{i j k}, \quad i \in R, j \in L, k \in S \\
X d(j, k+1)-X a(i, k+1) \geq h_{i j k}-M\left(1-c_{i j k}\right), \quad i \in R, j \in L, k \in S .
\end{gathered}
$$

3.3. The solution method of proposed model using ACS. In the proposed algorithm, it is supposed that the trains play the role of cities (nodes) in the TSP. The dispatched trains from left to right and also dispatched trains from right to left form two independent subnetworks of the TSP. According to the definition, selected path of each ant in the trains' network indicates the sequence of train dispatching.

For instance, in Figure 3.1 which includes 7 trains ( 3 dispatching trains from right to left and 4 dispatching trains from left to right), if an ant chooses the path from the start node of train 1 , train 3 , and train 2 it means the dispatching sequence is trains $1,3,2$. 


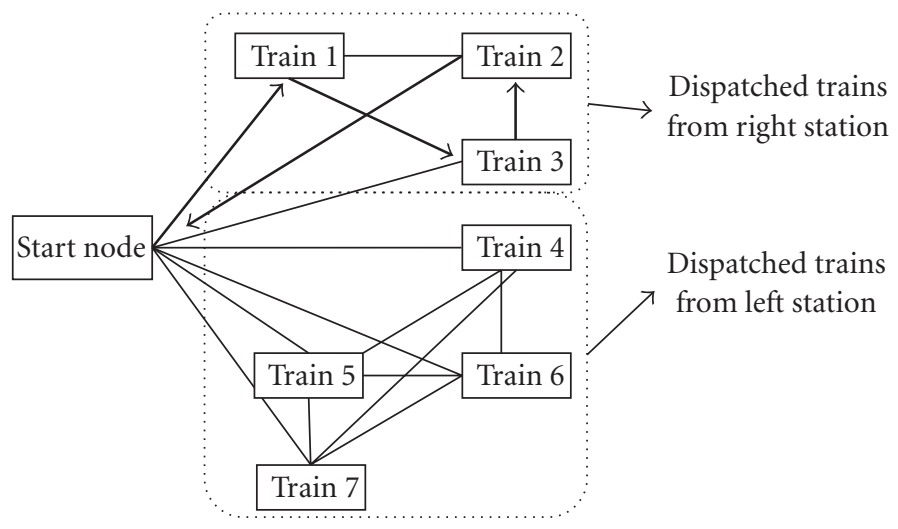

FIGURE 3.1. Problem's graph for the example of seven trains.

In this algorithm, a colony consists of $2 \times n$ ants where $n$ is number of the nodes (trains) of the TSP. The ants are allocated in $n$ groups. One of the ants of each group builds the sequence of dispatched trains from the right to left station and another ant is allocated to build the sequence of dispatched trains from left to right.

At first, both ants are placed at the figurative node of zero (the start node). Then, one of the ants is chosen from the first group randomly. The first chosen ant chooses a train in its train group by using the pseudorandom-proportional rule (3.1), (3.2). The arrival and departure times of the train from start station to the final station are calculated. Then another ant chooses its train which goes the opposite direction. The arrival and departure times of this train from each station are determined in regard to reconciliation of any collision incurred with the opposite train. In the case that the obtained times are true in (3.14), a collision occurs if the chosen train is the dispatched train from the left station:

$$
X a(i, k)+h_{i j k}>X d(j, k), \quad X d(i, k-1)-h_{i j k}<X d(j, k-1) .
$$

In this equation $j$ is the selected left station train, $i$ indicates the chosen right station train from the group of dispatched trains, and $k$ is a track section in which the collision occurred. In this case for collision resolution between two trains, the departure time of the chosen train from the related station is changed as follows:

$$
X d(j, k)=X a(i, k)+h_{i j k}
$$

The arrival and departure times of this train to its last station is calculated based on this time.

In the case that obtained times are true in (3.16), therefore, a collision occurs if the chosen train is the dispatched train from right station,

$$
X a(i, k-1)+h_{i j k}>X d(j, k-1), \quad X d(i, k)-h_{i j k}<X d(j, k) .
$$


In this equation, $j$ is the selected right station train, $i$ indicates the chosen train from the group of dispatched trains from left station, and $k$ is a track section in which the collision occurred. In this case for resolution of collision between two trains, departure time of the above selected train from related station changes as follows:

$$
X d(j, k-1)=X a(i, k-1)+h_{i j k}
$$

Once collision has been reconciled the chosen trains are omitted from the set of trains. Then randomly an ant is selected again. This ant chooses a train from its group. The arrival and departure times of this train are identified with its chosen sequence in its group. When the arrival and departure times from a section were identified, the collision condition of chosen train with dispatched chosen train in opposite direction is checked. In the case of collision, it is removed. This operation continues in the same way so that all the arrival and departure times from all stations are identified and there are not any collisions in the sections. Then the next train is chosen by other ants. This procedure continues until ants choose all the trains of their own group. (Refer to Figure 3.2.)

\section{Analysis of the model}

To analyze the solution results obtained from ACS-TS, they are compared with those of exact optimization method of the train scheduling model. For this purpose, computations are carried out for 45 problems including 3 to 8 trains and 2 to 8 track sections. The headway and dwell times are, respectively, considered 0.3 and 0.1 time units for all the trains and stations. The trip times are considered as a randomly selected number in the range of 2 to 15 time unit. For the created problem set, according to Dorigo and Gambardella $[36,37]$, the initial values for the global evaporation coefficient of pheromone, local evaporation coefficient of pheromone, pheromone initial amount on edges, and ACS parameter are, respectively, set to $0.1,0.1,0.000005$, and 0.9 .

Figure 4.1(a) shows sensitivity of the run times with respect to variation of number of track sections for solving the problems with exact algorithms and ACS-TS. In a similar manner, the sensitivity of the run times with respect to variation of number of trains for solving the train scheduling problems have been shown in Figure 4.1(b). Table 4.1 shows the results in more detail.

The time function of solving the problems with exact methods in relation to number of trains is obtained using MATLAB software and the results are completely an indictor of the NP complexity of the problem

$$
\operatorname{time}(s)=0.01181 e^{1.467 \times \text { number of trains }},
$$

while the time function of solving by ACS appears to a linear function in the range studied,

$$
\text { time }(s)=1.702 \times \text { number of trains }-2.738 \text {. }
$$

Similarly, the time functions of solving the problems with the exact and ACS methods in relation to the number of track sections are obtained. The exact methods (4.3) show 


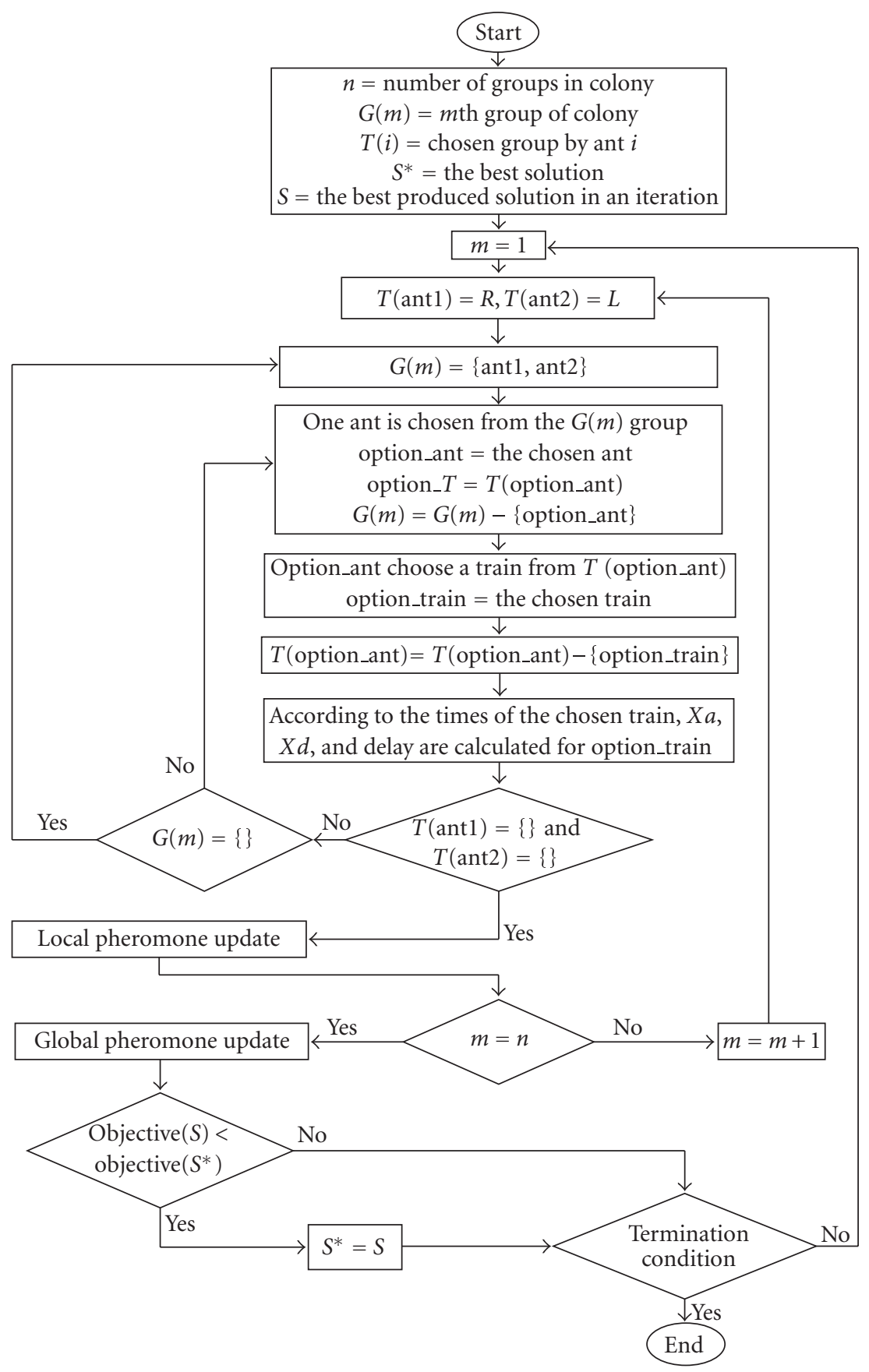

FIGURE 3.2. ACS-TS algorithm flowchart. 


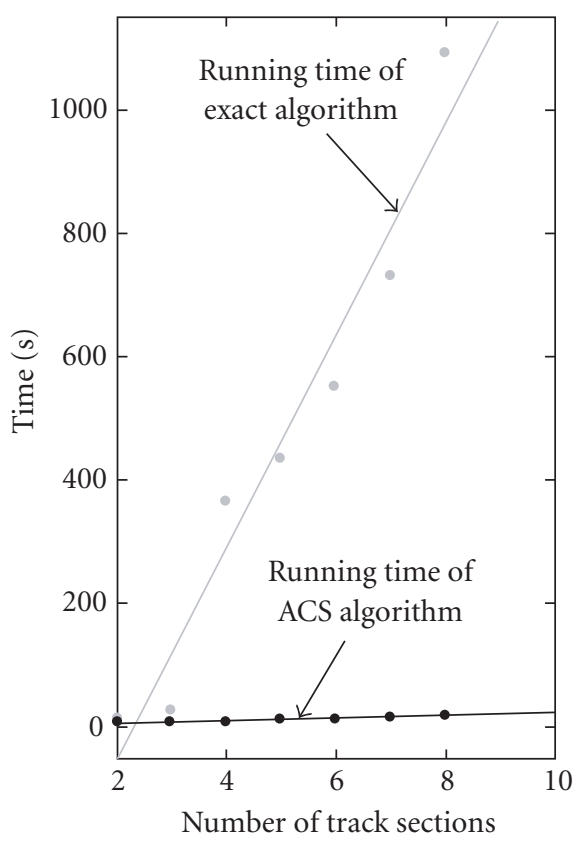

(a)

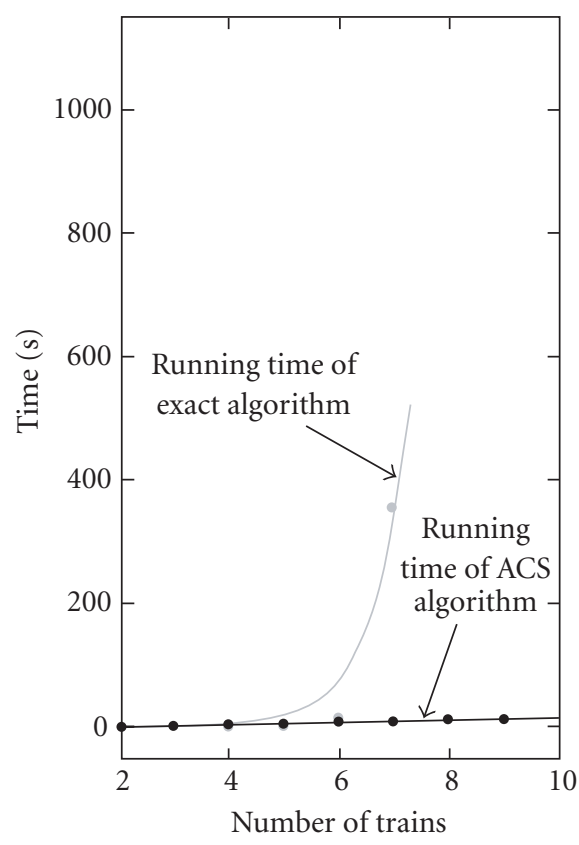

(b)

Figure 4.1. Run times of solving the train scheduling problems.

a fast increasing time function in comparison to the ACS method (4.4)

$$
\begin{aligned}
& \operatorname{time}(s)=172.6 \times \text { number of track sections }-403.6, \\
& \operatorname{time}(s)=1.75 \times \text { number of track sections }+3.107
\end{aligned}
$$

It was significant that in the created set of 45 problems the overall delay amount in dispatching trains from both methods was almost equal. However, the proposed ACS method showed considerable time savings in comparison to the exact solution method.

\section{The case study}

In this section, to clarify the use of the proposed algorithm, a problem with 30 trains and 4 track sections is solved.

5.1. Determination of ACS algorithm parameters. At first, according to Dorigo and Gambardella $[36,37]$ the initial values for parameters are set to the following values:

(i) global evaporation coefficient of pheromone, $\rho=0.1$;

(ii) local evaporation coefficient of pheromone, $\xi=0.1$;

(iii) pheromone initial amount on edges, $\tau_{i j}=0.000005$ for all $i$ and $j$;

(iv) ACS parameter, $q_{0}=0.9$. 
TABLE 4.1. Comparison of the results of the proposed algorithm with exact solutions.

\begin{tabular}{|c|c|c|c|c|c|c|c|c|}
\hline \multirow{2}{*}{ Problem } & \multirow{2}{*}{ \# Trains } & \multirow{2}{*}{$\begin{array}{l}\text { \# Eastbound } \\
\text { trains }\end{array}$} & \multirow{2}{*}{$\begin{array}{c}\text { \# Westbound } \\
\text { trains }\end{array}$} & \multirow{2}{*}{$\begin{array}{l}\text { \# Track } \\
\text { sections }\end{array}$} & \multicolumn{2}{|c|}{ Time } & \multicolumn{2}{|c|}{ Solution } \\
\hline & & & & & ACS & Exact & ACS & Exact \\
\hline 1 & 3 & 2 & 1 & 2 & 0 & 0 & 5.3 & 5.3 \\
\hline 2 & 4 & 3 & 1 & 2 & 0 & 0 & 16.9 & 16.9 \\
\hline 3 & 5 & 3 & 2 & 2 & 1 & 1 & 35 & 33.7 \\
\hline 4 & 5 & 2 & 3 & 2 & 1 & 7 & 34.8 & 31.9 \\
\hline 5 & 6 & 3 & 3 & 2 & 4 & 2 & 50.7 & 49.4 \\
\hline 6 & 7 & 3 & 4 & 2 & 7 & 20 & 80.3 & 76.9 \\
\hline 7 & 7 & 4 & 3 & 2 & 7 & 22 & 82.6 & 76.6 \\
\hline 8 & 8 & 5 & 3 & 2 & 8 & $*$ & 124 & $*$ \\
\hline 9 & 8 & 4 & 4 & 2 & 8 & $*$ & 123.8 & $*$ \\
\hline 10 & 8 & 3 & 5 & 2 & 8 & $*$ & 122.3 & $*$ \\
\hline 11 & 3 & 2 & 1 & 3 & 0 & 0 & 3.9 & 3.9 \\
\hline 12 & 4 & 3 & 1 & 3 & 1 & 2 & 14.1 & 14.1 \\
\hline 13 & 5 & 3 & 2 & 3 & 2 & 1 & 35.1 & 32 \\
\hline 14 & 5 & 2 & 3 & 3 & 2 & 1 & 30.5 & 29.3 \\
\hline 15 & 6 & 3 & 3 & 3 & 7 & 4 & 50.3 & 50.3 \\
\hline 16 & 7 & 3 & 4 & 3 & 9 & 35 & 82.4 & 78 \\
\hline 17 & 7 & 4 & 3 & 3 & 9 & 47 & 82.8 & 78.5 \\
\hline 18 & 8 & 5 & 3 & 3 & 10 & $*$ & 121.6 & $*$ \\
\hline 19 & 8 & 4 & 4 & 3 & 10 & $*$ & 114.2 & $*$ \\
\hline 20 & 8 & 3 & 5 & 3 & 10 & $*$ & 116.2 & $*$ \\
\hline 21 & 3 & 2 & 1 & 4 & 2 & 0 & 6.6 & 6.6 \\
\hline 22 & 4 & 3 & 1 & 4 & 5 & 0 & 14.2 & 14.2 \\
\hline 23 & 5 & 3 & 2 & 4 & 6 & 1 & 32 & 32 \\
\hline 24 & 5 & 2 & 3 & 4 & 6 & 5 & 35 & 31 \\
\hline 25 & 6 & 3 & 3 & 4 & 8 & 9 & 52.6 & 52.6 \\
\hline 26 & 7 & 3 & 4 & 4 & 9 & 1495 & 78.3 & 77.2 \\
\hline 27 & 7 & 4 & 3 & 4 & 9 & 97 & 83.6 & 81.1 \\
\hline 28 & 8 & 5 & 3 & 4 & 11 & $*$ & 121.1 & $*$ \\
\hline 29 & 8 & 4 & 4 & 4 & 11 & $*$ & 124.3 & $*$ \\
\hline 30 & 8 & 3 & 5 & 4 & 11 & $*$ & 125.3 & $*$ \\
\hline 31 & 3 & 2 & 1 & 5 & 3 & 0 & 3.9 & 3.9 \\
\hline 32 & 4 & 3 & 1 & 5 & 5 & 3 & 12.8 & 12.8 \\
\hline 33 & 5 & 3 & 2 & 5 & 8 & 1 & 27.8 & 27.8 \\
\hline 34 & 5 & 2 & 3 & 5 & 8 & 6 & 31.8 & 30.3 \\
\hline 35 & 6 & 3 & 3 & 5 & 11 & 17 & 46.7 & 46.7 \\
\hline 36 & 7 & 3 & 4 & 5 & 12 & 1648 & 71.5 & 70.7 \\
\hline 37 & 7 & 4 & 3 & 5 & 12 & 172 & 79.5 & 73.6 \\
\hline 38 & 8 & 5 & 3 & 5 & 15 & * & 121.6 & $*$ \\
\hline 39 & 8 & 4 & 4 & 5 & 15 & $*$ & 99.7 & $*$ \\
\hline 40 & 8 & 3 & 5 & 5 & 15 & $*$ & 121 & $*$ \\
\hline 41 & 7 & 4 & 3 & 6 & 15 & 301 & 60.8 & 58.7 \\
\hline 42 & 7 & 2 & 5 & 6 & 13 & 87 & 70.4 & 60.7 \\
\hline 43 & 7 & 3 & 4 & 7 & 15 & 87 & 80.9 & 77.3 \\
\hline 44 & 7 & 5 & 2 & 7 & 15 & 901 & 75.7 & 72.8 \\
\hline 45 & 7 & 4 & 3 & 8 & 18 & 557 & 72.6 & 69 \\
\hline
\end{tabular}

(* is used to show that computer was not able to solve the problem in a reasonable time.) 
ACS-TS: train scheduling using ant colony system

TABLE 5.1. Summary results of the favorable $q_{0}$ determination.

\begin{tabular}{lllccc}
\hline$q_{0}$ & $\begin{array}{c}\text { Mean of } \\
\text { solutions }\end{array}$ & $\begin{array}{l}\text { Standard } \\
\text { deviation }\end{array}$ & $\begin{array}{c}\text { Minimum } \\
\text { solution }\end{array}$ & $\begin{array}{c}\text { Maximum } \\
\text { solution }\end{array}$ & $\begin{array}{c}\text { Selection } \\
\text { measure }\end{array}$ \\
\hline 0 & 2630.57 & 28.78464 & 2598.1 & 2669.7 & 76846.36 \\
0.05 & 2613.9 & 23.36417 & 2587.5 & 2655.7 & 62048.23 \\
0.1 & 2619.34 & 27.01367 & 2563.5 & 2657.9 & 71799.63 \\
0.15 & 2618.83 & 31.19651 & 2566.5 & 2657.3 & 82898.49 \\
0.2 & 2615.92 & 38.79 & 2562.5 & 2677.3 & 103852.5 \\
0.25 & 2629.84 & 28.97601 & 2573.7 & 2673.5 & 77467.37 \\
0.3 & 2615.04 & 23.12196 & 2586.5 & 2663.8 & 61592.27 \\
0.35 & 2627.26 & 25.99633 & 2565.2 & 2654.1 & 68996.87 \\
0.4 & 2628.58 & 27.8667 & 2554.5 & 2650.3 & 73855.11 \\
0.45 & 2610.66 & 30.77482 & 2543.9 & 2658.5 & 81814.85 \\
0.5 & 2622.42 & 25.8411 & 2572.1 & 2663 & 68814.86 \\
0.55 & 2617.56 & 24.43116 & 2570.5 & 2649.5 & 64730.37 \\
0.6 & 2623.13 & 33.53807 & 2560.4 & 2669.5 & 89529.89 \\
0.65 & 2623.09 & 22.86732 & 2574.1 & 2669.1 & 61035.16 \\
0.7 & 2620.33 & 20.14812 & 2599.3 & 2669.1 & 53777.35 \\
0.75 & 2630.27 & 22.72595 & 2580.3 & 2660.2 & 60455.58 \\
0.8 & 2617.45 & 27.02596 & 2561.3 & 2651.5 & 71659.35 \\
0.85 & 2597.84 & 24.9848 & 2558.5 & 2632.7 & 65777.49 \\
$\mathbf{0 . 9}$ & $\mathbf{2 6 1 1 . 1 8}$ & $\mathbf{1 8 . 1 6 9 8}$ & $\mathbf{2 5 7 8 . 3}$ & $\mathbf{2 6 3 6 . 7}$ & $\mathbf{4 7 9 0 8 . 3 2}$ \\
0.95 & 2591.86 & 28.32114 & 2550.5 & 2631.5 & 74527.09 \\
1 & 2636.34 & 25.21671 & 2591.9 & 2674.5 & 67442.1 \\
\hline
\end{tabular}

Also, according to the definition of the problem, the number of ants in the colony of the problem is considered as twice as the number of trains and the fixed initial value $\tau_{0}=0.012$ that is obtained by $\tau_{0}=1 /\left(n \cdot L_{n n}\right)$ where $n$ is the number of trains and $L_{n n}$ is the solution cost produced by a heuristic method. (For further study refer to Dorigo and Gambardella $[36,37]$.) Furthermore by considering this fact that in the proposed algorithm, the length (cost) of arcs does not have a meaning therefore by supposing $\beta=0$, the length effect of edges is omitted in ACS.

Then the best parameter values are experimentally adjusted. For this purpose, based on the best parameters values previously found, the parameter values are iterated incrementally and then the algorithm runs ten times. After that according to the least value of the mean multiplied by the standard deviation from ten runs the best parameter value is chosen. In the train scheduling problem we are looking for the best reliable solution with the least amount of delay, therefore the least value of the mean multiplied by the standard deviation is considered as the election measure. After this step the best value was chosen and then the problem is solved with these best parameters.

5.1.1. $q_{0}$ parameter. In determining $q_{0}$, the parameter value is iterated from 0 to 1 by increments of 0.05 , and as it is clear from Table 5.1, according to the least value of the mean multiplied by the standard deviation from ten runs that its favorable value is supposed as $q_{0}=0.9$. 
TABLE 5.2. Summary results of the favorable $\rho$ determination.

\begin{tabular}{lllccc}
\hline$\rho$ & $\begin{array}{c}\text { Mean of } \\
\text { solutions }\end{array}$ & $\begin{array}{c}\text { Standard } \\
\text { deviation }\end{array}$ & $\begin{array}{c}\text { Minimum } \\
\text { solution }\end{array}$ & $\begin{array}{c}\text { Maximum } \\
\text { solution }\end{array}$ & $\begin{array}{c}\text { Selection } \\
\text { measure }\end{array}$ \\
\hline 0 & 2628.44 & 27.94233 & 2583.1 & 2670.1 & 73444.74 \\
0.05 & 2600.7 & 20.27588 & 2551.5 & 2620.5 & 52731.47 \\
0.1 & 2606 & 27.39233 & 2540.9 & 2645.9 & 71384.42 \\
0.15 & 2603.78 & 17.2209 & 2582.5 & 2633.3 & 44839.43 \\
0.2 & 2588.5 & 28.33796 & 2536.9 & 2619.1 & 73352.81 \\
0.25 & 2593.2 & 26.77399 & 2561.5 & 2641.9 & 69430.32 \\
0.3 & 2587.66 & 24.97052 & 2549.1 & 2625.9 & 64615.23 \\
0.35 & 2589.32 & 17.24367 & 2571.7 & 2629.4 & 44649.37 \\
0.4 & 2576.96 & 28.79507 & 2539.9 & 2632.9 & 74203.74 \\
0.45 & 2577.88 & 19.50213 & 2546.3 & 2611.7 & 50274.14 \\
0.5 & 2582.38 & 19.9787 & 2549.9 & 2616.3 & 51592.59 \\
0.55 & 2566.6 & 22.23656 & 2527.9 & 2589.9 & 57072.35 \\
0.6 & 2583.35 & 27.84422 & 2526.9 & 2629.5 & 71931.36 \\
0.65 & 2568.3 & 21.06097 & 2540.7 & 2606.3 & 54090.89 \\
0.7 & 2567.27 & 18.33176 & 2539.9 & 2605.1 & 47062.58 \\
0.75 & 2563.59 & 24.66326 & 2527.9 & 2618.4 & 63226.5 \\
0.8 & 2568.37 & 27.3426 & 2519.5 & 2609.3 & 70225.92 \\
0.85 & 2560.96 & 18.90045 & 2515.9 & 2580.9 & 48403.3 \\
0.9 & 2559.38 & 18.65171 & 2522.5 & 2591.1 & 47736.81 \\
0.95 & 2567.03 & 25.03464 & 2532.5 & 2617.9 & 64264.68 \\
1 & 2574.25 & 20.65662 & 2546.7 & 2605.7 & 53175.31 \\
\hline & & & & & \\
\hline
\end{tabular}

5.1.2. $\rho$ parameter. Based on $q_{0}=0.9$, the $\rho$ value is determined. In Table 5.2, the summary of results based on the iterations from 0 to 1 by increments of 0.05 for determining $\rho$ value is put forward. The best value based on the least value of the mean multiplied by the standard deviation from ten runs that is supposed as $\rho=0.35$.

5.1.3. $\xi$ parameter. Based on $q_{0}=0.9$ and $\rho=0.35$, the value of $\xi$ is determined. Table 5.3 shows the results summary based on iterations from 0 to 1 by increments of 0.05 for determining $\xi$ value. The most favorable value based on the least value of the mean multiplied by the standard deviation from ten runs that is supposed as $\xi=0.2$.

5.1.4. $\tau_{0}$ parameter. Based on $q_{0}=0.9, \rho=0.35$, and $\xi=0.2$, the value of $\tau_{0}$ is determined. Table 5.4 shows the results summary of determining $\tau_{0}$ value based on iterations from 0 to 0.0004 by steps of 0.00002 . The best value based on the least value of the mean multiplied by the standard deviation from ten runs that equals $\tau_{0}=0$.

5.2. The results of running the model. After adjusting the parameters, the proposed algorithm for the problem with 30 trains was run. The time-distance graph of the trains traveling is shown in Figure 5.1. The amount of delay in this state equals 2492.1. Figure 5.2 is the indicator of convergence in improving the solutions in each cycle from running the 
20 ACS-TS: train scheduling using ant colony system

TABLE 5.3. Summary results of the favorable $\xi$ determination.

\begin{tabular}{lllccc}
\hline$\xi$ & $\begin{array}{l}\text { Mean of } \\
\text { solutions }\end{array}$ & $\begin{array}{c}\text { Standard } \\
\text { deviation }\end{array}$ & $\begin{array}{c}\text { Minimum } \\
\text { solution }\end{array}$ & $\begin{array}{c}\text { Maximum } \\
\text { solution }\end{array}$ & $\begin{array}{c}\text { Selection } \\
\text { measure }\end{array}$ \\
\hline 0 & 2585.92 & 23.95615 & 2548.9 & 2627.3 & 61948.7 \\
0.05 & 2585.91 & 18.74581 & 2556 & 2610.3 & 48474.98 \\
0.1 & 2578.24 & 18.5987 & 2557.5 & 2608.9 & 47951.91 \\
0.15 & 2588.6 & 21.44518 & 2546.5 & 2618.1 & 55512.98 \\
$\mathbf{0 . 2}$ & $\mathbf{2 5 8 4 . 8 9}$ & $\mathbf{1 1 . 8 0 6 4 4}$ & $\mathbf{2 5 6 7 . 1}$ & $\mathbf{2 5 9 9 . 7}$ & $\mathbf{3 0 5 1 8 . 3 6}$ \\
0.25 & 2588.44 & 26.72781 & 2554.7 & 2619.1 & 69183.34 \\
0.3 & 2603.4 & 21.13712 & 2572.7 & 2635.9 & 55028.37 \\
0.35 & 2587.3 & 37.42581 & 2534.7 & 2638.5 & 96831.79 \\
0.4 & 2593.22 & 28.9329 & 2524.7 & 2635.3 & 75029.38 \\
0.45 & 2607 & 27.42979 & 2554.7 & 2654.9 & 71509.46 \\
0.5 & 2598.39 & 22.40111 & 2564.9 & 2639.1 & 58206.83 \\
0.55 & 2587.54 & 34.91702 & 2532.9 & 2632.3 & 90349.18 \\
0.6 & 2587.65 & 26.78081 & 2541.9 & 2624.5 & 69299.36 \\
0.65 & 2584.9 & 19.57618 & 2552.5 & 2608.1 & 50602.46 \\
0.7 & 2580.33 & 19.84485 & 2539.9 & 2599.6 & 51206.25 \\
0.75 & 2592.96 & 12.03884 & 2571.5 & 2608.9 & 31216.24 \\
0.8 & 2592.04 & 14.82912 & 2565.9 & 2613.7 & 38437.66 \\
0.85 & 2587.7601 & 18.94173 & 2561.1 & 2618.1 & 49016.66 \\
0.9 & 2593.03 & 13.87228 & 2566.7 & 2612.5 & 35971.23 \\
0.95 & 2588.26 & 20.32815 & 2543.5 & 2614.1 & 52614.54 \\
1 & 2591.96 & 13.64015 & 2571.9 & 2612.5 & 35354.73 \\
\hline
\end{tabular}

TABle 5.4. Summary results of the favorable $\tau_{0}$ determination.

\begin{tabular}{lllccc}
\hline$\tau_{0}$ & $\begin{array}{l}\text { Mean of } \\
\text { solutions }\end{array}$ & $\begin{array}{l}\text { Standard } \\
\text { deviation }\end{array}$ & $\begin{array}{c}\text { Minimum } \\
\text { solution }\end{array}$ & $\begin{array}{c}\text { Maximum } \\
\text { solution }\end{array}$ & $\begin{array}{c}\text { Selection } \\
\text { measure }\end{array}$ \\
\hline $\mathbf{0}$ & $\mathbf{2 5 4 0 . 9 2}$ & $\mathbf{1 8 . 8 1 4 2 9}$ & $\mathbf{2 5 1 5 . 9}$ & $\mathbf{2 5 7 1 . 5}$ & $\mathbf{4 7 8 0 5 . 5 9}$ \\
0.00002 & 2589.4 & 26.4162 & 2547.9 & 2619.9 & 68402.11 \\
0.00004 & 2594.78 & 30.84649 & 2546.7 & 2642.9 & 80039.87 \\
0.00006 & 2611.66 & 30.25474 & 2541.5 & 2651.1 & 79015.1 \\
0.00008 & 2610.71 & 23.94718 & 2562.1 & 2635.9 & 62519.16 \\
0.0001 & 2597.31 & 36.71574 & 2514.5 & 2637.8 & 95362.15 \\
0.00012 & 2625.12 & 26.19728 & 2577.5 & 2655.7 & 68771 \\
0.00014 & 2621.44 & 21.47894 & 2578.3 & 2644.8 & 56305.75 \\
0.00016 & 2621.24 & 20.82969 & 2583.5 & 2654.5 & 54599.62 \\
0.00018 & 2617.38 & 22.21835 & 2586.7 & 2652.1 & 58153.87 \\
0.0002 & 2618.43 & 20.91507 & 2575.7 & 2644.3 & 54764.64 \\
0.00022 & 2608.24 & 21.54067 & 2578.9 & 2662.5 & 56183.24 \\
0.00024 & 2620 & 25.23564 & 2572.7 & 2650.7 & 66117.39 \\
0.00026 & 2617.64 & 20.5229 & 2578.9 & 2654.5 & 53721.56 \\
0.00028 & 2634.96 & 27.93267 & 2581.9 & 2671.3 & 73601.46 \\
0.0003 & 2620.7 & 28.01809 & 2567.7 & 2661.9 & 73427.01 \\
0.00032 & 2613.15 & 20.18378 & 2591.1 & 2646.5 & 52743.25 \\
0.00034 & 2620.72 & 22.6618 & 2584.5 & 2652 & 59390.24 \\
0.00036 & 2625.21 & 23.63972 & 2596.7 & 2668.3 & 62059.24 \\
0.00038 & 2605.77 & 20.65301 & 2582.3 & 2645.2 & 53816.99 \\
0.0004 & 2612.01 & 25.06234 & 2576.1 & 2650.9 & 65463.09 \\
\hline
\end{tabular}




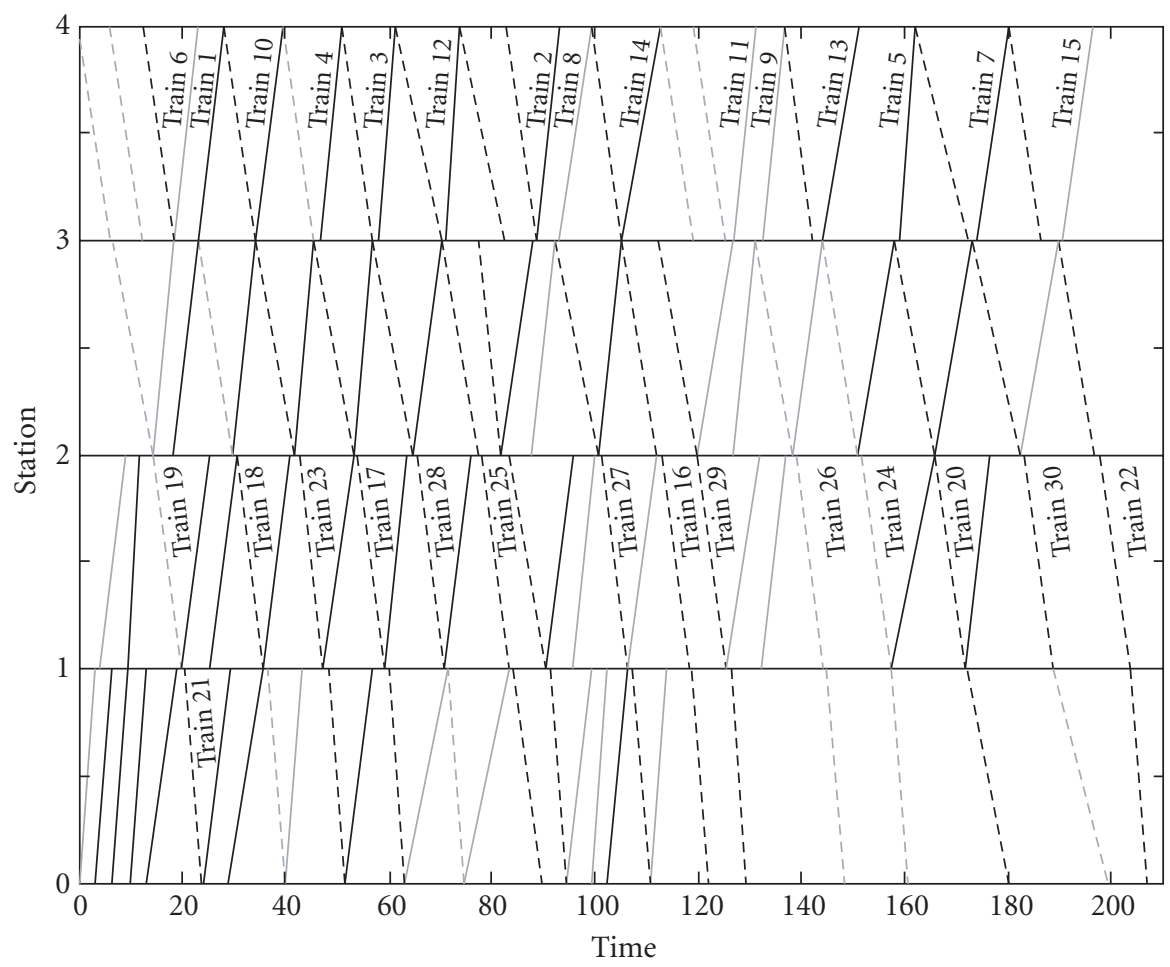

FIGURE 5.1. Time-distance graph of the trains traveling.

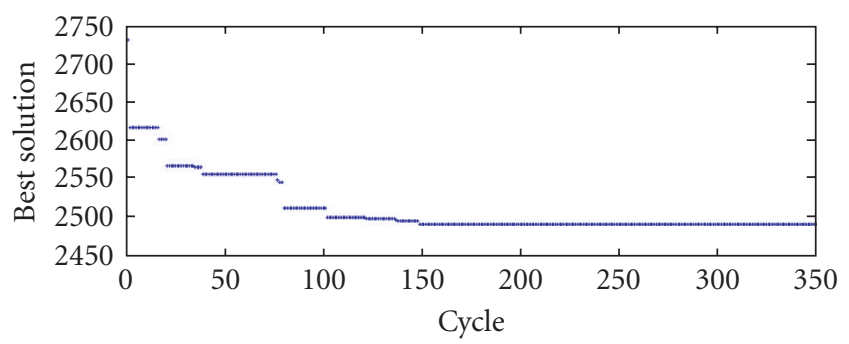

Figure 5.2. Convergence indicator in improving the solutions.

algorithm. Figure 5.3 shows the number of the dwelled trains in each time in the intermediate stations. Maximum number of the trains dwelled at the same time in stations 2, 3 , and 4 are, respectively, equal to 3, 2, and 3 trains.

\section{Conclusion}

This paper developed an algorithm for the train scheduling problem using the ant colony system metaheuristic called ACS-TS. At first, a mathematical model for a kind of train 


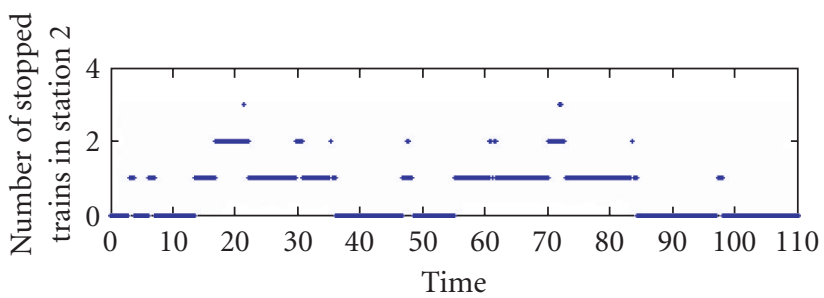

(a)

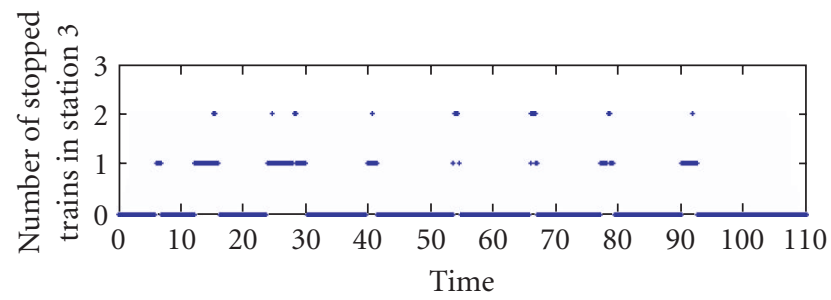

(b)

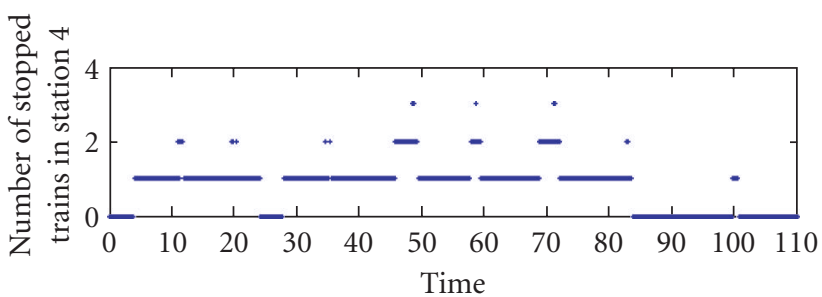

(c)

Figure 5.3. Number of the dwelled trains in each time in the intermediate stations.

scheduling problem was developed and then the algorithm based on ACS was presented to solve the problem. The problem was considered as a traveling salesman problem wherein cities in the TSP represent the trains. ACS determined the sequence of trains dispatched on the graph of the TSP. Using the sequences obtained and removing for collisions incurred, train scheduling was determined. Numerical examples in small and medium sizes were solved using ACS-TS and compared to exact optimum solutions to check for quality and accuracy. Comparison of the solutions showed that ACS-TS results in good quality and time savings. A case study was presented to illustrate the solution.

\section{References}

[1] I. Amit and D. Goldfarb, The timetable problem for railways, Developments in Operations Research 2 (1971), 379-387.

[2] S. Araya and K. Abe, An optimal rescheduling for online train traffic control in disturber situations, Proceedings of the 22nd IEEE Conference on Decision and Control, Texas, December 1983, pp. 489-494.

[3] A. A. Assad, Models for rail transportation, Transportation Research 14 B (1980), 101-114. 
[4] O. Baboglu, H. Meling, and A. Montresor, Anthill: a framework for the development of agent based peer-to-peer systems, Tech. Rep. UBLCS-2001-09, Department of Computer Science, University of Bologna, Bologna, 2001.

[5] B. Barán and R. Sosa, AntNet routing algorithm for data networks based on mobile agents, Intelligencia Artificial 12 (2001), 75-84.

[6] A. Baykasoglu, T. Dereli, and I. Sabuncu, An ant colony algorithm for solving budget constrained and unconstrained dynamic facility layout problems, to appear in Omega.

[7] J. E. Bell and P. R. McMullen, Ant colony optimization techniques for the vehicle routing problem, Advanced Engineering Information 18 (2004), 41-48.

[8] L. Bianchi, L. M. Gambardella, and M. Dorigo, An ant colony optimization approach to the probabilistic traveling salesman problem, Mathematical Modeling and Algorithms 3 (2004), no. 4, 403-425.

[9] J. A. Bland, Layout of facilities using an ant system approach, Engineering Optimization 32 (1999), no. 1, 101-115.

[10] __ Space-planning by ant colony optimization, International Journal of Computer Applications in Technology 12 (1999), no. 6, 320-328.

[11] _ Optimal structural design by ant colony optimization, Engineering Optimization 33 (2001), 425-443.

[12] C. Blum, Beam-ACO-hybridizing ant colony optimization with beam search: an application to open shop scheduling, Computers \& Operations Research 32 (2005), no. 6, 1565-1591.

[13] E. Bonabeau, F. Henaux, S. Guerin, D. Snyers, P. Kuntz, and G. Theraulaz, Routing in telecommunication networks with "Smart" ant-like agents, Proceedings of the 2nd International Workshop on Intelligent Agents for Telecommunication Applications (IATA '98), Lectures Notes in AI, vol. 1437, Springer, New York, 1998.

[14] G. S. Brodal and R. Jacob, Time-dependent networks as models to achieve fast exact time-table queries, Electronic Notes in Theoretical Computer Science 92 (2004), 3-15.

[15] B. Bullnheimer, R. F. Hartl, and C. Strauss, An improved ant system algorithm for the vehicle routing problem, Annals of Operations Research 89 (1999), 319-328.

[16] X. Cai and C. H. Goh, A fast heuristic for the train scheduling problem, Computers and Operation Research 21 (1994), no. 5, 499-510.

[17] M. Carey and D. Lockwood, A model, algorithms and strategy for train pathing, Operational Research Society 46 (1985), 988-1005.

[18] B. Chen and P. T. Harker, Two moments estimation of the delay on single-track rail lines with scheduled traffic, Transportation Science 24 (1990), no. 4, 261-275.

[19] Y. Cheng, Hybrid simulation for resolving resource conflicts in train traffic rescheduling, Computers in Industry 35 (1998), no. 3, 233-246.

[20] T. Chiang, H. Hau, H. Chiang, S. Ko, and C. Hsieh, Knowledge-based system for railway scheduling, Data \& Knowledge Engineering 27 (1998), no. 3, 289-312.

[21] V. Cicirello, A game-theoretic analysis of multi-agent systems for shop floor routing, Tech. Rep. CMU-RI-TR-01-28, Robotics Institute, Carnegie Mellon University, Pennsylvania, 2001.

[22] A. Colorni, M. Dorigo, V. Maniezzo, and M. Trubian, Ant system for job shop scheduling, Operations Research, Statistics and Computer Science 34 (1994), no. 1, 39-53.

[23] J. F. Cordeau, P. Toth, and D. Vigo, A survey of optimization models for train routing and scheduling, Transportation Science 32 (1998), 380-404.

[24] O. Cordon, I. Fernandez de Viana, F. Herrera, and L. Moreno, A new ACO model integrating evolutionary computation concepts: the best-worst ant system, Abstract Proceedings of ANTS2000 - From Ant Colonies to Artificial Ants: A Series of International Workshops on Ant Algorithms (M. Dorigo, M. Middendorf, and T. Stutzle, eds.), Brussels, 2000, pp. 22-29.

[25] D. Costa and A. Hertz, Ants can colour graphs, Journal of the Operational Research Society 48 (1997), 295-305. 
[26] J. E. Cury, F. A. C. Gomide, and M. J. Mendes, A methodology for generation of optimal schedules for an underground railway system, IEEE Transaction on Automatic Control 25 (1980), no. 2, 217-222.

[27] L. M. de Campos, J. M. Fernández-Luna, J. A. Gámez, and J. M. Puerta, Ant colony optimization for learning Bayesian networks, International Journal of Approximate Reasoning 31 (2002), no. 3, 291-311.

[28] M. Dessouky and R. C. Leachman, A simulation modeling methodology for analyzing large complex rail networks, Simulation 65 (1995), no. 2, 131-142.

[29] G. Di Caro and M. Dorigo, AntNet: a mobile agents approach to adaptive routing, Artificial Intelligence Research 9 (1997), 317-365.

[30] _ Extending antNet for best-effort quality-of-service routing, Presentation at ANTS '98 From Ant Colonies to Artificial Ants: 1st International Workshop on Ant Colony Optimization, Brussels, October 1998.

[31] K. F. Doerner, W. J. Gutjahr, R. F. Hartl, C. Strauss, and C. Stummer, Pareto ant colony optimization with ILP preprocessing in multiobjective project portfolio selection, to appear in European Journal of Operational Research.

[32] K. F. Doerner, R. F. Hartl, and M. Reimann, Cooperative Ant Colonies for Optimizing Resource Allocation in Transportation. Applications of Evolutionary Computing, Lecture Notes in Computer Science (LNCS), vol. 2037, Springer, Berlin, 2000.

[33] _ CompetAnts for problem solving: the case of full truckload transportation, Central European Journal of Operations Research 11 (2003), no. 2, 115-141.

[34] M. Dorigo and G. Di Caro, The ant colony optimization meta-heuristic, New Ideas in Optimization (D. Corne, M. Dorigo, and F. Glover, eds.), McGraw-Hill, London, 1999, pp. 11-32.

[35] M. Dorigo, G. Di Caro, and L. M. Gambardella, Ant algorithms for discrete optimization, Artificial Life 5 (1999), no. 2, 137-172.

[36] M. Dorigo and L. M. Gambardella, Ant colonies for the traveling salesman problem, BioSystems 43 (1997), no. 2, 73-81.

[37] _ Ant colony system: a cooperative learning approach to the traveling salesman problem, IEEE Transactions on Evolutionary Computation 1 (1997), no. 1, 53-66.

[38] M. Dorigo, V. Maniezzo, and A. Colorni, Positive feedback as a search strategy, Tech. Rep. 91016, Dipartimento di Elettronica, Politecnico di Milano, Milano, 1991.

[39] J. Dréo and P. Siarry, Continuous interacting ant colony algorithm based on dense heterarchy, Future Generation Computer Systems 20 (2004), 841-856.

[40] J. Eggers, D. Feillet, S. Kehl, M. O. Wagner, and B. Yannou, Optimization of the keyboard arrangement problem using an ant colony algorithm, European Journal of Operational Research 148 (2003), no. 3, 672-686.

[41] O. Engelhardt-Funke and M. Kolonko, Analysing stability and investments in railway networks using advanced evolutionary algorithms, International Transactions in Operational Research 11 (2004), no. 4, 381-394.

[42] M. Fabinkue, A swarm intelligence approach to constraint satisfaction, Proceedings of the 6th Conference on Integrated Design and Process Technology (IDPT '02), Texas, June 2002.

[43] M. Fischetti, J. Salazar-Gonzales, and P. Toth, The generalized traveling salesman problem and orienteering problem, Traveling Salesman Problem and Its Variations (G. Gutin and A. P. Punnen, eds.), Kluwer Academic, Dordrecht, 2002, pp. 609-663.

[44] P. Forsyt and A. Wren, An ant system for bus driver scheduling, Proceedings of the 7th International Workshop on Computer-Aided Scheduling of Public Transport Preprints, Center for Transportation Studies, MIT, Massachusetts, 1997, pp. 405-421.

[45] O. Frank, Two-way traffic on a single line of railway, Operations Research 14 (1965), 801-811.

[46] L. M. Gambardella and M. Dorigo, An ant colony system hybridized with a new local search for the sequential ordering problem, INFORMS Journal on Computing 12 (2000), no. 3, 237-255. 
[47] L. M. Gambardella, E. Taillard, and G. Agazzi, MACS-VRPTW: vehicle routing problem with time windows, New Ideas in Optimization (D. Corne, M. Dorigo, and F. Glover, eds.), McGrawHill, London, 1999, pp. 63-76.

[48] L. M. Gambardella, E. Taillard, and M. Dorigo, Ant colonies for the quadratic assignment problem, Operational Research Society 50 (1999), no. 2, 167-176.

[49] J. A. Gámez and J. M. P. Puetra, Searching for the best elimination sequence in Bayesian networks by using ant colony optimization, Pattern Recognition Letters 23 (2002), no. 1-3, 261-277.

[50] X. Gandibleux, X. Delorme, and K. Tkindt, An Ant Colony Optimization Algorithm for The Set Packing Problem, submitted to Ants '04, 4th International Workshop on Ant Colony Optimization and Swarm Intelligence, 2004.

[51] K. Ghoseiri, F. Szidarovszky, and M. J. Asgharpour, A multi-objective train scheduling: model and solution, Transportation Research 38 B (2004), 927-952.

[52] M. F. Gorman, An application of genetic and tabu searches to the freight railroad operating plan problem, Annals of Operations Research 78 (1998), 51-69.

[53] M. Gravel, W. Price, and C. Gagné, Scheduling continuous casting of aluminum using a multiple objective ant colony optimization metaheuristic, European Journal of Operational Research $\mathbf{1 4 3}$ (2002), no. 1, 218-229.

[54] G. Gutin and A. P. Punnen, The Traveling Salesman Problem and Its Variations, Combinatorial Optimization, vol. 12, Kluwer Academic, Dordrecht, 2002.

[55] M. Heusse, S. Guerin, D. Snyers, and P. Kuntz, Adaptive agent-driven routing and load balancing in communication networks, Advances in Complex Systems 1 (1998), 237-254.

[56] A. Higgins and E. Kozan, Modeling train delays in urban networks, Transportation Science 32 (1998), no. 4, 346-357.

[57] A. Higgins, E. Kozan, and L. Ferreira, Heuristic techniques for single line train scheduling, Journal of Heuristics 3 (1997), no. 1, 43-62.

[58] C. L. Huntley, D. E. Brown, D. E. Sappington, and B. P. Markowicz, Freight routing and scheduling at CSX, Transportation Interfaces 25 (1995), no. 3, 58-71.

[59] Y. Iida, Timetable preparation by A.I approach, Proceeding of European Simulation Multiconference, Nice, 1988, pp. 163-168.

[60] V. K. Jayaraman, B. D. Kulkarni, and K. Gupta, Dynamic optimization of fed-batch bioreactors using the ant algorithm, Biotechnology Progress 17 (2001), no. 1, 81-88.

[61] V. K. Jayaraman, B. D. Kulkarni, S. Karale, and P. Shelokar, Ant colony framework for optimal design and scheduling of batch plants, Computers and Chemical Engineering 24 (2000), no. 8, 1901-1912.

[62] J. Jong and M. Wiering, Multiple ant colony systems for the bus stop allocation problem, Proceedings of the 13th Belgium-Netherlands Conference on Artificial Intelligence, Amsterdam, 2001, pp. 141-148.

[63] D. Jovanovic and P. T. Harker, A decision support system for train dispatching: an optimizationbased methodology, Journal of the Transportation Research Forum 30 (1990), no. 1, 25-37.

[64] M. H. Keaton, Designing optimal railroad operating plans: Lagrangian relaxation and heuristic approaches, Transportation Research Part B 23 (1989), no. 6, 415-431.

[65] K. Komaya and T. Fukuda, A knowledge-based approach for railway scheduling, The 7th IEEE Conference on Artificial Intelligence Applications, Florida, 1991, pp. 405-411.

[66] P. Korošec, J. Šilc, and B. Robič, Solving the mesh-partitioning problem with an ant-colony algorithm, Parallel Computing 30 (2004), no. 5-6, 785-801.

[67] R. D. Kraay and P. T. Harker, Real-time scheduling of freight railroads, Transportation Research Part B: Methodological 29 (1995), no. 3, 213-229.

[68] R. S. K. Kwan and P. Mistry, A co-evolutionary algorithm for train timetabling, Research Report Series 2003.13, School of Computing, University of Leeds, Leeds, 2003. 
[69] A. Lim, J. Lin, B. Rodrigues, and F. Xiao, Ant colony optimization with hill climbing for the bandwidth minimization problem, to appear in Applied Soft Computing.

[70] T. Lindner, Train schedule optimization in public rail transport, Ph.D. thesis, Technische Universitat, Braunschweig, 2000.

[71] V. Maniezzo, Exact and approximate nondeterministic tree-search procedures for the quadratic assignment problem, INFORMS Journal on Computing 11 (1999), no. 4, 358-369.

[72] V. Maniezzo and A. Carbonaro, An ANTS heuristic for the frequency assignment problem, Future Generation Computer Systems 16 (2000), no. 8, 927-935.

[73] V. Maniezzo, A. Carbonaro, M. Golfarelli, and S. Rizzi, ANTS for data warehouse logical design, Proceedings of the 4th Metaheuristics International Conference, Porto, 2001, pp. 249-254.

[74] V. Maniezzo and A. Colorni, The ant system applied to the quadratic assignment problem, IEEE Transactions on Data and Knowledge Engineering 11 (1999), no. 5, 769-778.

[75] V. Maniezzo, A. Colorni, and M. Dorigo, The ant system applied to the quadratic assignment problem, Tech. Rep. IRIDIA/94-28, IRIDIA, Université Libre de Bruxelles, Bruxelles, 1994.

[76] R. D. Martinelli and H. Teng, Optimization of railway operations using meural networks, Transportation Research 4c (1996), 33-49.

[77] P. R. Mcmullen, An ant colony optimization approach to addressing a JIT sequencing problem with multiple objectives, Artificial Intelligence in Engineering 15 (2001), no. 1, 309-317.

[78] R. Michel and M. Middendorf, An ACO algorithm for the shortest supersequence problem, New Ideas in Optimization (D. Corne, M. Dorigo, and F. Glover, eds.), McGraw Hill, London, 1999, pp. 51-61.

[79] S. Minton, M. D. Johnston, A. B. Philips, and P. Laird, Minimizing conflicts: a heuristic repair method for constraint satisfaction and scheduling problems, Artificial Intelligence 58 (1992), no. 1-3, 161-205.

[80] N. Monmarché, G. Venturini, and M. Slimane, There how pachycondyla apicalis ants suggest is new search algorithm, Future Generation Systems Computer 16 (2000), no. 8, 937-946.

[81] R. Montemanni, L. M. Gambardella, A. E. Rizzoli, and A. V. Donati, A new algorithm for a dynamic vehicle routing problem based on ant colony system, Tech. Rep. IDSIA-05-02, Istituto Dalle Molle di Studi sull'Intelligenza Artificiale (IDSIA), Manno, November 2002, ftp://ftp.idsia.ch/pub/techrep/IDSIA-23-02.pdf.gz.

[82] R. Montemanni, D. H. Smith, and S. M. Allen, An ANTS algorithm for the minimum-span frequency-assignment problem with multiple interference, IEEE Transactions on Vehicular Technology 51 (2002), no. 5, 949-953.

[83] K. Nachtigall and S. Voget, A genetic algorithm approach to periodic railway synchronization, Computers \& Operations Research 23 (1996), no. 5, 453-463.

[84] N. Nahas and M. Nourelfath, Ant system for reliability optimization of a series system with multiple-choice and budget constraints, Reliability Engineering and System Safety 87 (2005), no. $1,1-12$.

[85] C. E. Noon and J. C. Bean, A Lagrangian based approach for the asymmetric generalized traveling salesman problem, Operations Research 39 (1991), no. 4, 623-632.

[86] D. Pacciarelli and M. Pranzo, A Tabu search algorithm for the railway scheduling problem, Proceedings of the 4th Metaheuristic International Conference, Porto, 2001, pp. 16-20.

[87] Peat, Marwick, and Mitchell \& Co., Train dispatching simulation model: capabilities and description. USA, Report DOT-FR-4-5014-1, Federal Railroad Administration, Department of Transportation, Washington, DC, March 1975.

[88] E. R. Petersen, Over the road transit time for a single track railway, Transportation Science 8 (1974), 65-74.

[89] V. Ramos and F. Almeida, Artificial ant colonies in digital image habitats - a mass behavior effect study on pattern recognition, Proceedings of the 2nd International Workshop on Ant Algorithms - From Ant Colonies to Artificial Ants, September 2000. 
[90] M. Reimann and M. Laumanns, Savings based ant colony optimization for the capacitated minimum spanning tree problem, to appear in Computers and Operations Research.

[91] A. E. Rizzoli, A. V. Donati, L. M. Gambardella, N. Casagrande, and R. Montemanni, Time dependent vehicle routing problem with an ant colony system, Tech. Rep. IDSIA-17-03, Istituto Dalle Molle di Studi sull'Intelligenza Artificiale (IDSIA), Manno, 2002.

[92] A. Roli, C. Blum, and M. Dorigo, ACO for maximal constraint satisfaction problems, Proceeding of the 4th Metaheuristics International Conference, vol. 1, Porto, 2001, pp. 187-191.

[93] B. Scheuermann, K. So, M. Guntsch, M. Middendorf, O. Diessel, H. ElGindy, and H. Schmeck, FPGA implementation of population-based ant colony optimization, Applied Soft Computing 4 (2004), no. 3, 303-322.

[94] R. Schoonderwoerd, O. Holland, J. Bruten, and L. Rothkrantz, Ant based load balancing in telecommunications networks, Adaptive Behavior 5 (1996), no. 2, 169-207.

[95] M. Sepehri, Railway crew scheduling with grouping evolutionary algorithm, Amir Kabir Engineering Journal 14 (2003), no. 54, 565-577 (Persian).

[96] P. S. Shelokar, V. K. Jayaraman, and B. D. Kulkarni, An ant colony approach for clustering, Analytica Chimica Acta 509 (2004), no. 2, 187-195.

[97] L. Shi, J. Hao, J. Zhou, and G. Xu, Ant colony optimization algorithm with random perturbation behavior to the problem of optimal unit commitment with probabilistic spinning reserve determination, Electric Power Systems Research 69 (2004), no. 2-3, 295-303.

[98] K. Socha, M. Sampels, and M. Manfrin, Ant algorithms for the university course timetabling problem with regard to the state-of-the-art, Computer Science 2611 (2003), 334-345.

[99] M. Solimanpur, P. Vrat, and R. Shankar, Ant colony optimization algorithm to the inter-cell layout problem in cellular manufacturing, European Journal of Operational Research 157 (2004), no. 3, 592-606.

[100] _ An ant algorithm for the single row layout problem in flexible manufacturing systems, Computers \& Operations Research 32 (2005), no. 3, 583-598.

[101] T. Stutzle, An ant approach to the flow shop problem, Proceedings of the 6th European Congress on Intelligent Techniques and Soft Computing, vol. 3, Aachen, 1998, pp. 1560-1564.

[102] T. Stutzle and H. Hoos, MAX-MIN ant system, Future Generation Computer Systems 16 (2000), no. 8, 889-914.

[103] D. Subramanian, P. Druschel, and J. Chen, Ants and reinforcement learning: a case study in routing in dynamic networks, Proceedings of the International Joint Conference on Artificial Intelligence, Morgan Kaufmann, Nagoya, 1997, pp. 832-838.

[104] B. Szpigel, Optimal train scheduling on a single-track railway, Operational Research '72 (M. Ross, ed.), OR'72, North-Holland, Amsterdam, 1972, pp. 343-351.

[105] E. G. Talbi, O. Rouxb, C. Fonlupt, and D. Robillard, Parallel ant colonies for the quadratic assignment problem, Future Generation Computer Systems 17 (2001), no. 4, 441-449.

[106] E. S. Tzafestas, Experiences from the development and use of simulation software for complex systems education, Proceedings of the World Conference on the WWW and Internet (WebNet2000), Texas, November 2000.

[107] R. Van der Put, Routing in the faxfactory using mobile agents, Tech. Rep. R \& D-SV-98-276, KPN Research, Groningen, 1998.

[108] M. C. Van Wezel, J. N. Kok, J. N. Van den Berg, and W. Van Kampen, Genetic improvement of railway timetables, Computer Science 866 (1994), 566-574.

[109] K. Vijayakumar, G. Prabhaharan, P. Asokan, and R. Saravanan, Optimization of multi-pass turning operations using ant colony system, International Journal of Machine Tools \& Manufacture 43 (2003), no. 15, 1633-1639.

[110] A. Wade and S. Salhi, An ant system algorithm for the mixed vehicle routing problem with backhauls, Metaheuristics: Computer Decision-Making, Kluwer Academic, Dordrecht, 2004, pp. 699-719. 


\section{ACS-TS: train scheduling using ant colony system}

[111] T. White, B. Pagurek, and F. Oppacher, Connection management using adaptive mobile agents, Proceedings of International Conference on Parallel and Distributed Processing Techniques and Applications (PDPTA '98), CSREA Press, Nevada, 1998, pp. 802-809.

[112] I. K. Yu and Y. H. Song, A novel short-term generation scheduling technique of thermal units using ant colony search algorithms, International Journal of Electrical Power and Energy Systems 23 (2001), no. 6, 471-479.

[113] Z. Zhou and Z. Liu, Intelligent ant-based algorithm with applications in dynamic routing optimization of telecommunication networks, Telecommunications Science 14 (1998), no. 11, 10-13.

[114] M. Zweben, E. Davis, E. Daun, and M. J. Deale, Scheduling and rescheduling with iterative repair, IEEE Transaction on Systems, Man, and Cybernetics 23 (1993), no. 6, 1588-1596.

Keivan Ghoseiri: School of Railway Engineering, Iran University of Science and Technology, Tehran 16846-13114, Iran

E-mail address: ghoseiri@iust.ac.ir

Fahimeh Morshedsolouk: School of Railway Engineering, Iran University of Science and Technology, Tehran 16846-13114, Iran

E-mail address: fahimeh_morshedsolouk@yahoo.com 


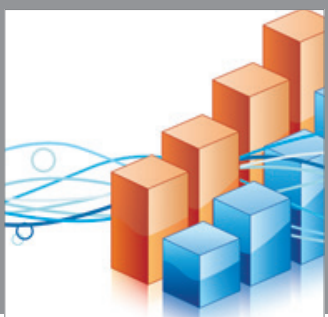

Advances in

Operations Research

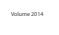

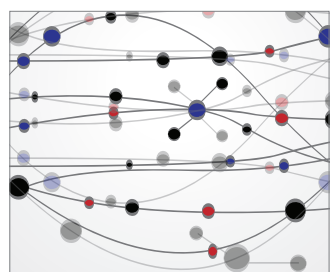

\section{The Scientific} World Journal
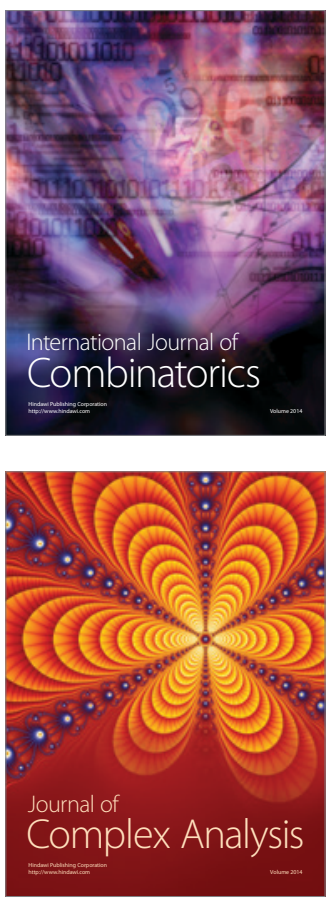

International Journal of

Mathematics and

Mathematical

Sciences
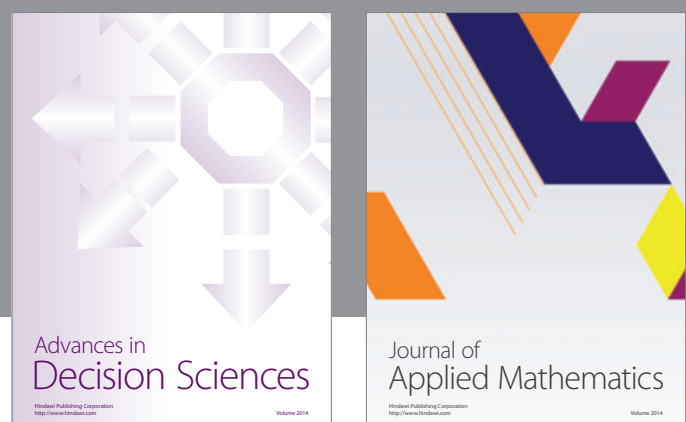

Journal of

Applied Mathematics
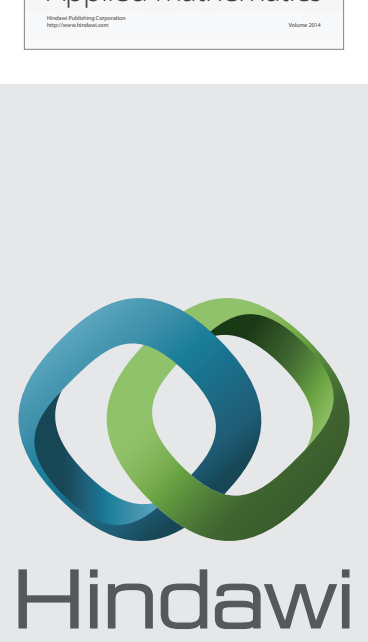

Submit your manuscripts at http://www.hindawi.com
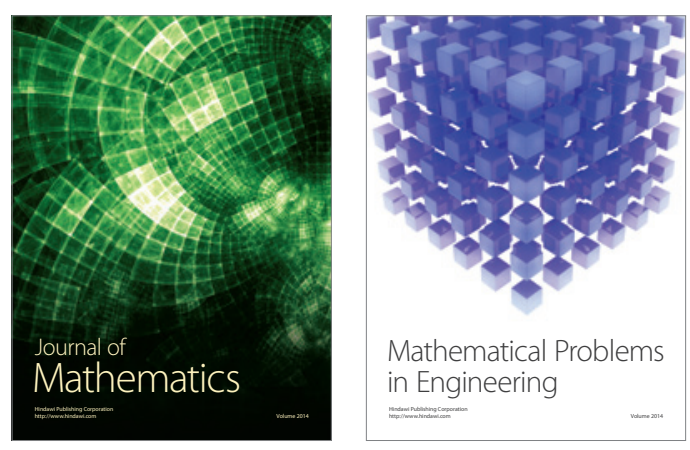

Mathematical Problems in Engineering
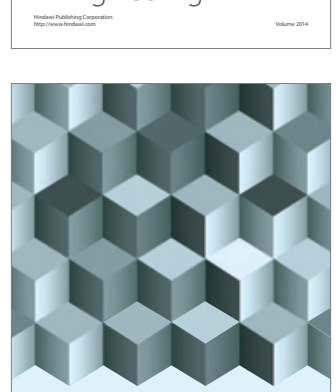

Journal of

Function Spaces
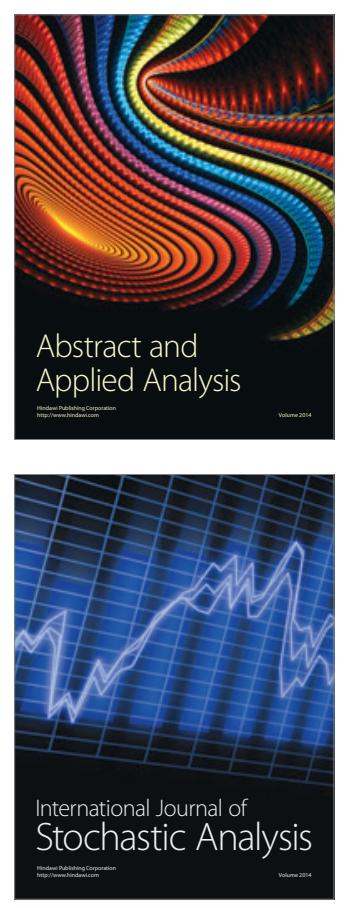

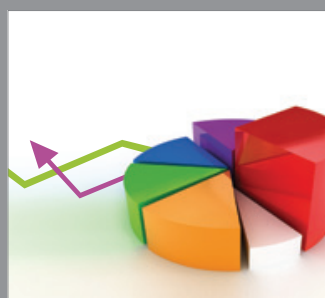

ournal of

Probability and Statistics

Promensencen
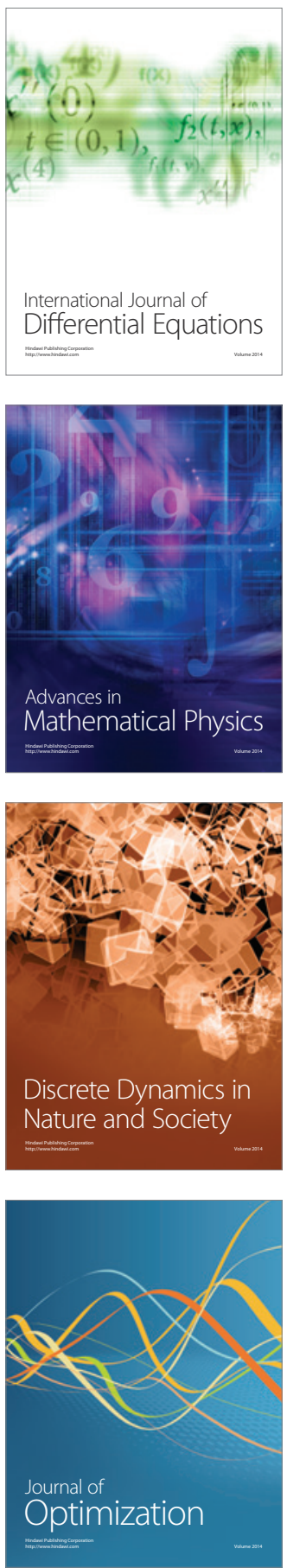